
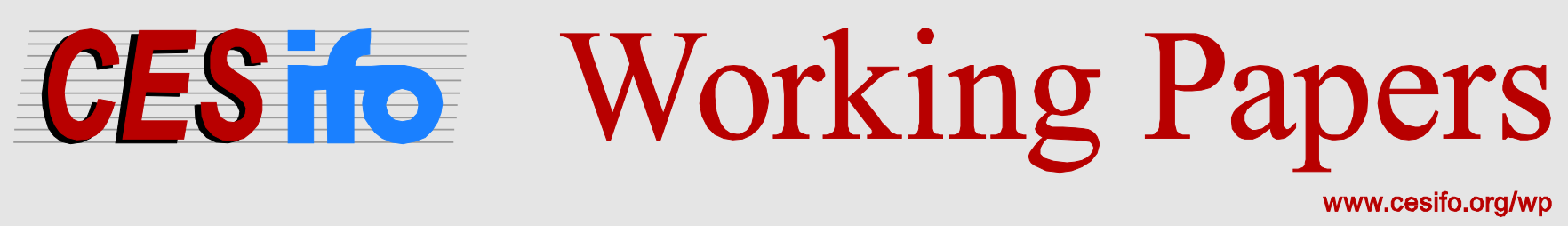

\title{
Externalities in Risky Resource Markets - Optimal Taxes, Leakage and Divestment
}

\author{
Florian Habermacher
}

\author{
CESIFO WORKING PAPER NO. 5865 \\ CATEGORY 10: ENERGY AND ClimATE ECONOMICS \\ APRIL 2016
}

Presented at CESifo Area Conference on Energy and Climate Economics, October 2015

An electronic version of the paper may be downloaded

- from the SSRN website: Www.SSRN.com

- from the RePEc website: Www.RePEc.org

- from the CESifo website: www.CESifo-group.org/wp 


\title{
Externalities in Risky Resource Markets - Optimal Taxes, Leakage and Divestment
}

\begin{abstract}
We consider a global externality of resource use, with the example of greenhouse gas emissions from fossil fuels. A region concerned about climate change may reduce its fuel deposit offer, reduce fuel consumption, and withdraw investments into global fuel extraction. We study leakage rates and optimal taxes on these three activities in a framework with uncertain fuel market returns. Without uncertainty, the unilateral investment tax is welfare-neutral: costless but ineffective divestment. With uncertainty, the regional investment choice affects global fuel usage, and correspondingly the optimal regional fuel policy contains a investment tax in addition to taxes on deposit supply and consumption. Even absent terms-of-trade effects, the optimal unilateral investment tax is a non-marginal fraction of the perceived climate disutility for a region of any size. Equivalently, a rational portfolio optimizer with relevant concern for the climate problem withdraws parts or all of her funds from the carbon sector.
\end{abstract}

JEL-Codes: Q540, Q410, H230, H210.

Keywords: unilateral climate policy, optimal carbon tax, investment uncertainty, carbon leakage, resource rent tax, fossil fuel market, carbon divestment, fuel investment tax, desposit supply tax, exhaustible resources.

\author{
Florian Habermacher \\ University of St. Gallen \\ Swiss Institute for International Economics \\ and Applied Economic Research \\ Bodanstrasse 8 \\ Switzerland - 9000 St. Gallen \\ florian.habermacher@unisg.ch
}

April 10, 2016

For helpful remarks I am particularly thankful to participants of the CESifo conference on Energy and Climate Economics October 2015 in Munich, and for suggestions on an earlier version I am thankful to Rick van der Ploeg, Dieter Helm, and Johnathan Inkley. 


\section{Introduction}

We consider first- and second-best climate mitigation in presence of investment risk aversion in the fossil fuel sector. To limit risk exposure is a key target of investors generally, and impressive movements of prices for fuels underline its importance in the fuel extractive sector (Figure 1). We provide a financial and economic equilibrium framework to study the implications of the risk vs. expected return tradeoff on rational choices and policies of global, regional, or individual, climate concerned actors.

We find, in particular, that a climate concerned region can, alongside more traditional fuel demand and resource deposit supply measures, impose a tax on regional investments into global fuel extraction projects in order to reduce global fuel use. Equivalently, individual, concerned investors may want to reconsider the position of fossil fuel assets in their portfolios, even if they will not always fully divest from the sector.

This first result contradicts the conventional wisdom of individuals' investment changes being irrelevant due to offsetting adjustments by third parties. The conventional view would be realistic only in a simplified world, absent uncertainty. Such a deterministic world would not only mean that unilateral divestment is without effect on global fuel use, but it would equally imply that divestment is irrelevant for the divestor's profit. Given how plagued the fuel sector is by uncertainty, a deterministic framework does, however, best serve as a counterfactual to a more realistic stochastic analysis. In a stochastic analysis we find that unilateral investment choices influence global emissions.

The analysis considers three broad categories of activities through which fuel-market actors influence the global fuel-market equilibrium: They may purchase fossil fuel for consumption; as resource owners they may offer deposits to the market; and as investors they may allocate capital to global resource extraction projects. A policymaker may intervene in any of these activities to influence aggregate fuel use and market prices. Greenhouse gas emissions are proportional to fuel use. Table 1 summarizes the actors and their activities.

In a simple, deterministic world with global policies, intervention in any one of the three activities is generally sufficient to achieve the optimal outcome. Whalley and Wigle (1991) show that in a standard framework, policies affecting demand and deposit supply are interchangeable, and it readily follows from our analysis that for global policies, this equivalence extends to the third activity, investment. If global policies are, however, infeasible, the best regional policy in a deterministic world would contain two distinct elements: a tariff on domestic fuel consumption, and one on domestic supply of resources (Hoel, 1994). ${ }^{1}$ A unilateral investment tariff would not benefit the climate because do-

\footnotetext{
${ }^{1}$ With multiple fuels, it can be shown that these components generally vary across fuels (Golombek et al., 1995; Habermacher, 2015).
} 

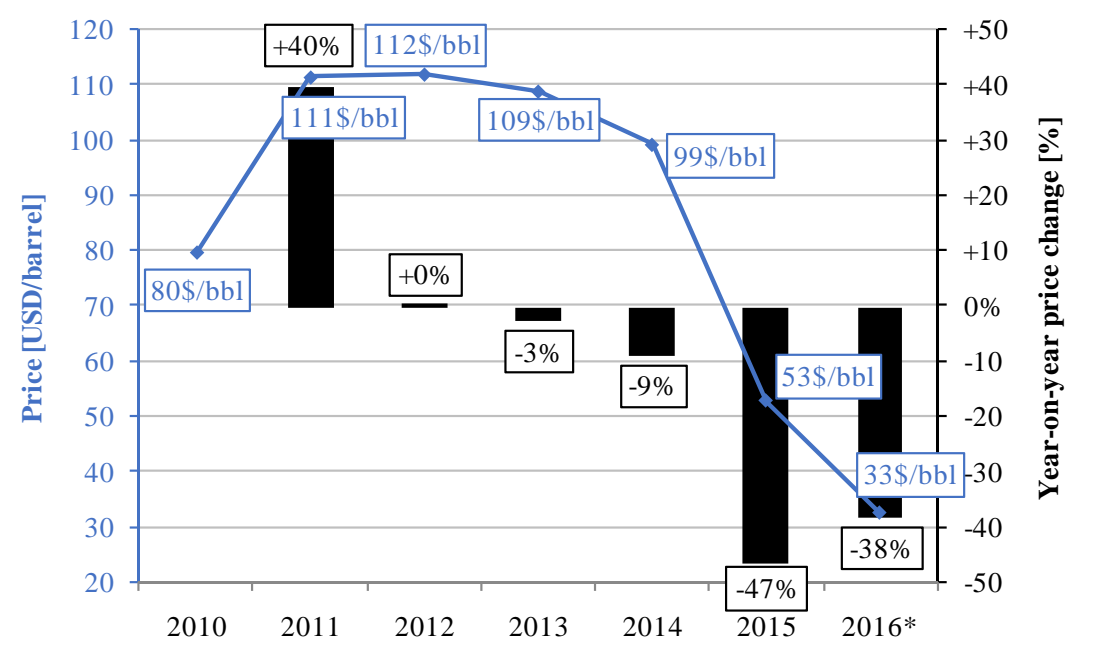

Figure 1: Oil price changes: Brent Crude

Data: Aurora Energy Research EOS: Annual average Brent crude spot, nominal. *Value as of February 2016.

mestic capital withdrawal from the sector would merely lead to a replacement by foreign capital.

We study the market when returns from extraction projects are uncertain. Optimal regional policy appears to contain a distinct tariff on regional investments into global fuel projects, alongside regional tariffs on consumption and deposit supply. We identify the optimal unilateral tariffs on the three activities, and show their relation to activity-specific interregional leakage rates.

The key to the explanation of the investment tax lies in the risk premium required to motivate investments: to compensate the risk associated with fuel extraction, investors require a premium on expected returns. This ultimately implies a cost associated with a non-marginal regional reduction of fuel investment, but it equally entails that foreign investors negate unilateral investment changes only partly, limiting leakage to a fraction smaller than $100 \%$. Conversely, without market risk, the unilateral investment change is both, fully offset by the response of investors from the passive region, and costless for the active region.

The regionally optimal tariffs are not directly dependent on the size of the policy-region, and the investment tax remains pertinent even if the risk structure warrants for the fuel sector to yield a lower rather than higher equilibrium return compared to alternative risky assets.

The analysis is based on a staged multi-region equilibrium model of a fuel-market with risk-averse, forward-looking, atomic agents. In stage 0 , policies are chosen. In stage 1 , the deposit and fuel markets clear: agents (i) demand fuel from the global market for consumption, (ii) offer domestic deposits that can be lifted at increasing costs, and (iii) 
decide on investment into global, risky deposit-to-fuel extraction projects with endogenous returns, as an alternative to investment into a riskless asset, or into other, imperfectly correlated, risky assets. In stage 2 , the stochastic component of the extraction costs is revealed, and the agents derive utility from fuel and numeraire consumption. Figure 2 gives an overview of the timeline of this strategic game.

To simplify the exposition, the analysis starts off with regions that are symmetric except for size, taste for climate protection, and feasibility of fuel-market taxes. Moreover, the unilateral tax is first presented for a small open economy (SOE), which idles terms-of-trade motives, and for risk only in the fuel market. We subsequently relax these assumptions, showing how the unilateral policy changes for a large open economy, considering regionspecific extraction costs and fuel consumption utilities. Further, we extend the model with a risky non-fuel asset as an investment alternative, with returns (positively or negatively) correlated to those from the resource-to-fuel projects. The key conclusions remain largely unaffected in all extensions, with the exception of terms-of-trade components entering the taxes chosen by the large open economy.

Literature has addressed various other aspects of uncertainty on resource markets. Dasgupta and Heal (1974) and Dasgupta and Stiglitz (1976) study a resource market where a substitute becomes available at an uncertain future date. Hoel (1978) analyzes the effect of risk aversion by consumers and firms in presence of uncertainty about the cost of future resource substitutes. Van der Ploeg (2012) considers the dynamic climate effect of the endogenous, uncertain emergence of a clean substitute for fossil fuels. ${ }^{2}$ The novelty in the present paper is the consideration of the risk spread motive of market actors in the design of unilateral climate policy, and the distinction between deposit supply, extraction, and consumption.

Beyond the implications for regional climate policy, our results have implications on whether climate-concerned investors should withdraw their funds from the fossil-fuel extractive sector, as currently urged by the fossil fuel divestment campaign. ${ }^{3}$ The small open economies modeled can be seen as proxies for individual or institutionalized investors. The limited carbon leakage rates mean that in terms of carbon-equivalent, a non-marginal share of the withdrawn funds results in global emission reductions in equilibrium; divestment effects are not generally 'zero-sum' for the climate. Furthermore, at least a partial divestment by investors can be an individually efficient climate measure, as indicated by the marginal-only costs for the first units of divestment from a purely financially optimized portfolio.

Section 2 introduces the model. Section 3 identifies the rules governing decentralized choices by the representative, regional agents, and identifies the global equilibrium in a

\footnotetext{
${ }^{2}$ Crabbé (1982) reviews further studies examining effects of uncertainties on resource markets. They tend to focus on global policies addressing inefficiencies other than climate change.

${ }^{3}$ E.g., Fossil Free, www.gofossilfree.org (accessed 2015-12-05).
} 
laissez-faire, i.e., without any policies. It also analyzes the globally optimal allocation, and establishes the set of global taxes for which this optimum obtains in a market equilibrium. We then identify the second-best solution achievable for a region imposing taxes unilaterally, facing a passive remainder of the world, in section 4, for both, a small or a large open economy. Section 5 discusses complications in the real world, including the timeconsistency problem, and links the analysis to the currently growing global divestment movement. Section 6 concludes.

\section{Model}

We distinguish three activities or choices of fuel market participants in a staged economy. First, selling of resources by deposit owners on a resource market in stage 1. Second, resource extraction investment, stretching from stage 1 to stage 2 : the allocation of capital for its employment in fuel extraction projects, subject to a particular market risk. These extraction investment projects may be thought of as including processes such as primary extraction, resource-to-fuel refinement, as well as financial and logistic aspects related to the handling of extracted fuel including transport. Third, fuel consumption in stage 2. The three activities reflect that, on a high level, the fuel market is characterized by some offer of resource deposits, a demand for consumable fuel, and mediators, exposed to substantial market risk, that extract and handle resources, transforming them into consumable fuels. The problem of market uncertainty is greatly simplified by assuming that investors absorb the market risk wholly and in form of a stochastic extraction cost component, revealed after investment decisions have been made.

In reality, part of the fuel market risk originates from short- and medium-term noise in the market clearing price due to slow response of demand and supply to prices. In this case, demand is exposed to some of the uncertainty that affects suppliers, and suppliers and demanders could conclude forward contracts to hedge against the risk. Often, fuel consumers do not conclude explicit price hedging contracts, and exhibit a rather priceinelastic demand over shorter periods. Major fuel producers are distinct actors on the market. The framework used captures the explicit risk considerations of fuel supply investors, and the more passive role of many fuel consumers. Table 1 summarizes the activities and the actors performing them.

Rather than considering all actors in Table 1 as independent, we combine deposit owners, investors, and consumers into representative regional agents that perform the three activities separately. This simplifies notation, but is otherwise equivalent to treating the actors separately with adequate regional, redistributive transfers in place.

We consider a world populated by a normalized unit mass of regionally homogenous agents. Population masses (and thus fractions) are $h_{r}$ in region $r$, so that $\sum_{r} h_{r}=1$. 


\begin{tabular}{|l|l|l|}
\hline Actors & Role & Key characteristic \\
\hline \hline Deposit owners & Own regional deposits, sell to investors & Continuum extractable at increasing costs \\
\hline Investors & Invest globally in deposits for extraction & Aversion to risk from uncertain returns \\
\hline Consumers & Buy and consume fuel from investors & Consume fuel with decreasing utility \\
\hline \hline Policymaker & Taxes regional actors' activities & Levies taxes, redistributes lump-sum \\
\hline
\end{tabular}

Table 1: Actors and activities

In the remainder we express regional variables in per-capita units (or intensities), except where otherwise noted. We denote $x_{r}$ the per-capita amount of fuel extracted from regional deposits. The regional endowment of resource deposits is characterized by a continuous, differentiable and convexly increasing, regional extraction cost curve $c_{r}(x)$ defining the deterministic part of the cumulative per-capita cost of extracting the cheapest amount $x$, per-capita, of resources in region $r, c_{r}(0)=0, c_{r}^{\prime}>0, c_{r}^{\prime \prime}>0 .{ }^{4}$ The $x$ 'th unit of regional resource extracted thus has a per-unit, deterministic extraction cost component $c_{r}^{\prime}(x)$. An additional, stochastic per-unit cost $k$ arises from extraction. We call the deterministic component $c$ the extraction cost, and the stochastic component $k$ the handling cost. Regional fuel-consumption utility is defined by a continuous, differentiable and concavely increasing function, $v_{r}(f), v_{r}^{\prime}>0, v_{r}^{\prime \prime}<0$, with $f$ the per-capita fuel consumption.

To simplify the exposition, the main part considers a handling cost $k$ that is homogenous across resource units. Annex D shows how the analysis extends to the case with a continuum of fields with field-specific, imperfectly correlated costs; results remain qualitatively unchanged.

Consumption of both, fuel and numeraire, takes place in stage 2 which we therefore use as reference point. By then, stage 1 revenues and costs are inflated by a gross return rate $R>1$ earned by risklessly invested capital.

We consider a globally integrated market for investments and fuel, abstracting from transport and transaction costs. As investors, regional agents can invest globally into the risky resource extraction projects, as an alternative to investment into the save asset that returns $R .^{5}$ Each unit of resource deposit purchased in stage 1 yields one unit of fuel in stage 2 after extraction. The unit-specific extraction cost $c_{r}^{\prime}(x)$ is assumed to accrue in stage 1 , while the stochastic handling cost $k(s)$ is attributed to stage 2 when the state of nature $s$ is being revealed and the investment decision has become irreversible.

\footnotetext{
${ }^{4}$ We adopt the Herfindahl (1967) concept of resource units being extractable individually, so that (given positive real-interest rates) profit-maximizing resource owners extract the fuels ordered in a sequence according to extraction costs: the resources with the lowest extraction costs are extracted first, and the ones with the highest extraction costs are extracted last.

${ }^{5}$ Annex $\mathrm{C}$ extends the analysis to the case with an additional, correlated risky non-fuel asset.
} 
Regional governments can levy taxes on the three activities of their regional agents, to influence the market outcome. For simplicity, we express the tax levels in stage 2 values, even though investment and deposit supply are naturally taxed in stage 1. All taxes are announced before any activity takes place (stage 0). The alternative of a government unable to commit before stage 1 to the stage 2 consumption tax is discussed in section 5.4 .

Let $\tilde{q}_{r}(x)$ be the trading price for which resource deposit owners sell the unextracted resources to the investors in stage 1 , after payment of a regional resource deposit supply $\operatorname{tax} \tau_{x}^{r}$. We call $p$ the global fuel price consumers face in stage 2 , before paying regional fuel taxes $\tau_{f}^{r}$. Agents from region $r$ investing into the globalized fuel market incur in stage 1 the extraction $\operatorname{costs} c_{i}^{\prime}(x)$ for extraction of unit $x$ in region $i$, and in stage 2 the revealed handling cost $k(s)$ and the domestic investment $\operatorname{tax} \tau_{z}^{r}$.

For an investor, usage of any unit of resource has the same value once the extraction cost has been paid: After expenditure of the extraction cost, which is $c_{r}^{\prime}(x)$ for the $x^{\prime}$ th unit of region $r$, all fuel units are of equal use to a global investor. We call this value $q$, attributed to stage 1 . In a competitive, interior solution, arbitrage between the competitively supplied resource units warrants for the equilibrium pre-extraction price of region $r$ 's $x$ 'th unit of deposit in stage 1 to become

$$
\tilde{q}_{r}(x)=q-c_{r}^{\prime}(x)
$$

Seen from stage 2, supply of $x_{r}$ units of resource deposit leads to the private deposit owner's profit

$$
\xi_{r} \equiv \int_{0}^{x_{r}} R \tilde{q}_{r}(x)-\tau_{x}^{r} \mathrm{~d} x=\left(R q-\tau_{x}^{r}\right) x_{r}-R c_{r}\left(x_{r}\right)
$$

where the second equality follows the substitution of $\tilde{q}_{r}$ using (1).

The per-unit payoff for an agent from region $r$ investing into an $x^{\prime}$ th unit of resource from region $i$ is $\tilde{\zeta}_{r}(s, i, x)=p-\left[\tilde{q}_{i}(x)+c_{i}^{\prime}(x)\right] R-k(s)-\tau_{z}^{r}=p-R q-k(s)-\tau_{z}^{r}$, where $\left[\tilde{q}_{i}(x)+c_{i}^{\prime}(x)\right] R$ is the opportunity cost of purchase and extraction of the resource, reflecting the return from investment into the alternative, secure asset, and the second equality follows the substitution of $\tilde{q}_{r}$ using (1). The payoff from investment into $z_{r}$ units of resource is therefore

$$
\zeta_{r}(s)=\left(p-R q-k(s)-\tau_{z}^{r}\right) z_{r},
$$

independently of how the investment is spread across the globally used resource deposits. Fuel consumption of $f_{r}$ units yields the private surplus

$$
\phi_{r} \equiv v_{r}\left(f_{r}\right)-\left(p+\tau_{f}^{r}\right) f_{r}
$$

Regionally collected taxes are recycled lump-sum, with a transfer $T_{r}$ to the representative 
regional agent,

$$
T_{r} \equiv \tau_{x}^{r} x_{r}+\tau_{f}^{r} f_{r}+\tau_{z}^{r} z_{r}
$$

We express resource and fuel units in terms of units of associated cradle-to-grave emissions and define climate damage $D$ as an increasing function of absolute global fuel consumption $F \equiv \sum_{r} h_{r} f_{r}$. The damage is perceived regionally with an absolute regional weight $\omega_{r}$, so that the regionally perceived damage is, per-capita,

$$
D_{r} \equiv \frac{\omega_{r}}{h_{r}} D(F)
$$

Let $y_{r}$ be the consumption index of the representative regional agent, seen from period 2, given as a simple linear combination of (2)-(6),

$$
y_{r}(s) \equiv \xi_{r}+\phi_{r}+\zeta_{r}(s)+T_{r}-D_{r}
$$

Taxes and transfers offset each other, simplifying $y_{r}$ to

$$
y_{r}(s)=\left(z_{r}-f_{r}\right) p+\left(x_{r}-z_{r}\right) R q-R c_{r}\left(x_{r}\right)+v_{r}\left(f_{r}\right)-k(s) z_{r}-\frac{\omega_{r}}{h_{r}} D(F)
$$

However, the individual agent is small and takes the transfer $T_{r}$ as given. The index relevant for the decentralized choices, $y_{r}^{d}$, accordingly preserves the incentive effects of the tax, writing

$$
y_{r}^{d}(s)=\left(R q-\tau_{x}^{r}\right) x_{r}-R c_{r}\left(x_{r}\right)+v_{r}\left(f_{r}\right)-\left(p+\tau_{f}^{r}\right) f_{r}+\left(p-R q-k(s)-\tau_{z}^{r}\right) z_{r}+T_{r}-\frac{\omega_{r}}{h_{r}} D(F) .
$$

Consumption utility $u_{r} \equiv u\left(y_{r}\right)$ has strictly positive and decreasing returns, $u^{\prime}>0$, $u^{\prime \prime}<0$.

We use $g_{r}$ as the set summarizing all regional activities, $g_{r} \equiv\left\{f_{r}, x_{r}, z_{r}\right\}$, or, occasionally and with special mentioning, as a placeholder for one of these activities. We ensure tractability by assuming a normal distribution of the handling cost. Purely for convenience and with no loss of generality we assume it to be mean-zero,

$$
k \sim N\left(0, \sigma^{2}\right)
$$

and we assume a constant absolute risk aversion (CARA) utility function,

$$
u(y) \equiv 1-e^{-\alpha y}
$$

with $\alpha>0$ the constant of absolute risk aversion, $-\frac{u^{\prime \prime}(y)}{u^{\prime}(y)}=\alpha$. Constant absolute risk aversion avoids direct income effects; investment decisions of the representative agent are not directly influenced by, e.g., climate damage, demand levels, or earned resource rents. 


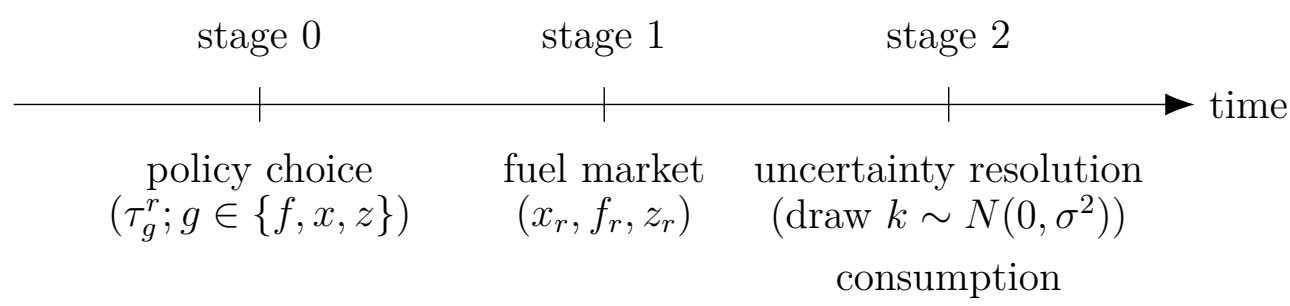

Figure 2: Timing of the game with strategic supply, investment, and consumption policy

Through the handling cost $k(s)$, consumption index and utility depend on the state of nature. We write the expected utility $\mathrm{E}_{s}\left[u_{r}\right]=\mathrm{E}_{s}\left[u\left(y_{r}(s)\right)\right]$.

The sector is in equilibrium, so market clearance conditions relate the three activities,

$$
\sum_{r} h_{r} f_{r}=\sum_{r} h_{r} x_{r}=\sum_{r} h_{r} z_{r}
$$

Figure 2 summarizes the timeline of this game.

In detail the decisions and activities are staged as follows:

\section{Stage 0: policy}

- policy choice

$-\tau_{x}^{r}$ : tax on regional deposit supply

- $\tau_{z}^{r}$ : tax on regional investments in extraction globally

$-\tau_{f}^{r}$ : tax on regional fuel consumption

\section{Stage 1: fuel market}

- choice of activity levels, clearing markets

$-x_{r}$ : regional deposit offer

$-z_{r}$ : regional investment in extraction globally

- $f_{r}$ : regional fuel consumption

Between stage 1 and stage 2: time passes

- safe real return $\mathrm{R}$

- extraction takes place

\section{Stage 2: uncertainty resolution and consumption}

- stochastic handling cost revealed

- extraction cost incurred 
- tax collection and lump-sum proceeds distribution

- consumption of fuel and numeraire

To simplify the discussion, we presume the parameters of the problem to be such that interior solutions obtain for all variables in all regions and situations considered. The necessary conditions are mostly standard and easily identified. Especially regional policies could, for some parametrizations, theoretically render activities such as resource offer or fuel investment slack. This seems mainly tangent to our main conclusions, and leaving reflections upon possible corner solutions as an exercise to the reader allows a more concise treatment here in the paper.

The setup warrants fuel investment to yield an excess return over the risk-free interest rate, to cover the uncertainty associated with fuel investment projects. Annex C analyzes an alternative setup that allows investment into an additional type of risky (non-fuel) assets. The key conclusions remain the same as with the setup introduced here. Figure 3 illustrates the relationship between the various costs and prices, for simplicity with the gross interest hypothetically set to unity, $R=1$. The active region $a$ imposes taxes on all three activities, while its trading partner region $b$ pursues a laissez-faire.

\section{Decentralized choices, laissez-faire, and global op- timum}

We start by assuming inter-regionally symmetric per-capita extraction costs and fuel consumption utilities. Section 4.2 extends to a more heterogeneous world.

\subsection{Decentralized choices}

Let $g_{r}$ be the set of regional activities fuel consumption $f_{r}$, resource offer $x_{r}$, and extraction investment $z_{r}, g_{r} \equiv\left\{f_{r}, x_{r}, z_{r}\right\}$. We consider decentralized activity choices $g_{r}^{*}$, maximizing the utility derived from private consumption $y_{r}^{d}$, taking prices and climate damage as given,

$$
g_{r}^{*} \equiv \underset{g_{r}}{\arg \max } \mathrm{E}_{s}\left[u\left(y_{r}^{d}\right)\right]
$$

Consumption $y_{r}^{d}$ from (8) is normally distributed with mean $\mu_{y, r}=\left(R q-\tau_{x}^{r}\right) x_{r}-$ $R c\left(x_{r}\right)+v\left(f_{r}\right)-\left(p+\tau_{f}^{r}\right) f_{r}+\left(p-R q-\tau_{z}^{r}\right) z_{r}+T_{r}-\frac{\omega_{r}}{h_{r}} D(F)$ and standard deviation $\sigma_{y, r}=\sigma z_{r}$. With the CARA utility $u$ from (10), this allows to rewrite the problem with 


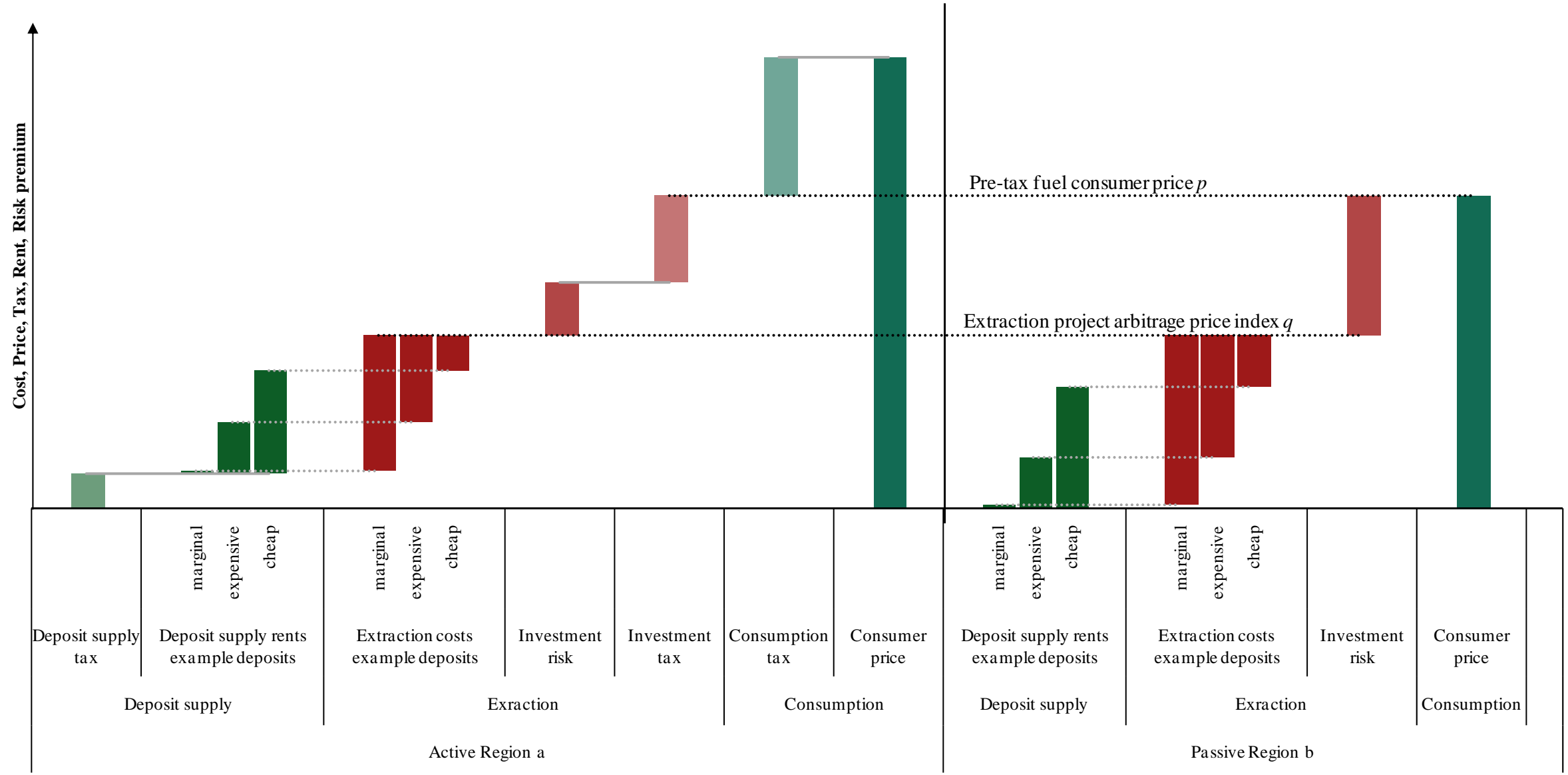


$g_{r}^{*}=\underset{g_{r}}{\arg \min } \log \mathrm{E}_{s}\left[\exp \left(-\alpha y_{r}^{d}\right)\right]$. Defining the risk-adjusted consumption level as

$$
\tilde{y}_{r} \equiv \mu_{y, r}-\frac{1}{2} \alpha \sigma_{y, r}^{2}
$$

and using the expectation rule for log-normal variables, $a \sim \mathcal{N}\left(\mu_{a}, \sigma_{a}\right) \Longrightarrow \mathrm{E}_{s}[a]=$ $\exp \left(\mu_{a}+\frac{1}{2} \sigma_{a}^{2}\right)$, the problem can be rewritten as

$$
g_{r}^{*}=\underset{g_{r}}{\arg \max } \tilde{y}_{r}
$$

The FOCs for an interior solution, $\partial \tilde{y}_{r} / \partial g_{r} \stackrel{!}{=} 0$, yield the single-valued activity choice functions

$$
\begin{aligned}
f_{r}^{*}\left(p+\tau_{f}^{r}\right) & =\left\{f \mid v^{\prime}(f)=p+\tau_{f}^{r}\right\}, \\
x_{r}^{*}\left(q-\tau_{x}^{r} / R\right) & =\left\{x \mid c^{\prime}(x)=q-\tau_{x}^{r} / R\right\}, \\
z_{r}^{*}\left(p-R q-\tau_{z}^{r}\right) & =\left\{z \mid z \alpha \sigma^{2}=p-R q-\tau_{z}^{r}\right\} .
\end{aligned}
$$

The uncertainty of $k(s)$ has a direct impact only on the investment choice $z_{r}$, for which the solution in (13) is inversely proportional to $k$ 's variance $\sigma^{2}$. We can isolate $z_{r}^{*}$ in the third equation in (13), but the form used here exposes that the risk cost from the marginal investment, $z \alpha \sigma^{2}$, equals the expected net return. Using $f_{r}^{*}$ and $x_{r}^{*}$ from (13) to substitute $p$ and $q$, we find

$$
z_{r}^{*} \alpha \sigma^{2}=v^{\prime}\left(f_{r}^{*}\right)-R c^{\prime}\left(x_{r}^{*}\right)-\tau_{f}^{r}-\tau_{x}^{r}-\tau_{z}^{r}
$$

The price-responsivenesses of these activity levels show that global demand decreases in the fuel price $p$, global supply increases in the time-adjusted resource price $q R$, and global investment increases in the price wedge $p-q R$ :

$$
\begin{aligned}
f_{r}^{* \prime}\left(p+\tau_{f}^{r}\right) & =1 / v^{\prime \prime}\left(f_{r}^{*}\right)<0, \\
x_{r}^{* \prime}\left(q-\tau_{x}^{r} / R\right) & =1 / c^{\prime \prime}\left(x_{r}^{*}\right)>0, \\
z_{r}^{* \prime}\left(p-R q-\tau_{z}^{r}\right) & =1 / \alpha \sigma^{2}>0 .
\end{aligned}
$$

It readily follows that the interior market equilibrium from the decentralized choices (13) is unique.

\subsection{Laissez-faire}

In the laissez-faire, that is, absent any taxes, $\tau_{g}^{r}=0$, the decentralized solution is symmetric across regions, and market clearance (11) implies that all activity levels take on 
the same value, $f^{l}$, for which we find a simple implicit expression after substitution in (14),

$$
\begin{aligned}
& x_{r}, f_{r}, z_{r}=f^{l}, \text { where } \\
& f^{l} \equiv\left\{f \mid f \alpha \sigma^{2}=v^{\prime}(f)-R c^{\prime}(f)\right\} .
\end{aligned}
$$

The LHS in the brackets is strictly increasing and the RHS strictly decreasing in $f$, so any possible interior solution is unique. The conditions for its existence are that the choke-price exceeds initial, time-adjusted extraction costs, $v^{\prime}(0)>R c^{\prime}(0)$, and that for an arbitrarily large amount of fuel, the marginal fuel consumption utility falls below the time-adjusted extraction costs with a premium to compensate the exaction cost risk, $\lim _{f \rightarrow \infty} v^{\prime}(f)<R c^{\prime}(f)+f \alpha \sigma^{2}$.

\subsection{Global optimum}

Consider a utilitarian planner's problem of maximizing global welfare $W \equiv \sum_{r} h_{r} \mathrm{E}_{s}\left[u\left(y_{r}\right)\right]$, subject to a global analogue to the regional budget constraint (7) to hold in each state of nature, and clearing markets,

$$
\begin{gathered}
g_{r}^{w}, y_{r}^{w} \equiv \underset{g_{r}, y_{r}}{\arg \max } W=\underset{g_{r}, y_{r}}{\arg \max } \sum_{r} h_{r} \mathrm{E}_{s}\left[u\left(y_{r}\right)\right] \\
\text { subject to } \quad \sum_{r} h_{r}\left[v\left(f_{r}\right)-R c\left(x_{r}\right)-k(s) z_{r}-\frac{\omega_{r}}{h_{r}} D(F)-y_{r}(s)\right]=0 \forall s \\
F=\sum_{r} h_{r} f_{r}=\sum_{r} h_{r} x_{r}=\sum_{r} h_{r} z_{r} .
\end{gathered}
$$

The state-contingent global budget constraint in (17) allows redistribution between the regions. Annex A uses a Lagrangian to show that the planner chooses regionally symmetric fuel consumption and deposit supply levels, $f^{w}$,

$$
\begin{aligned}
& f_{r}^{w}=x_{r}^{w}=f^{w}, \text { where } \\
& f^{w} \equiv\left\{f \mid f \alpha \sigma^{2}=v^{\prime}(f)-R c^{\prime}(f)-D^{\prime}(f) \sum_{r} \omega_{r}\right\}
\end{aligned}
$$

and that he redistributes between the regions such as to equalize the regional consumption indexes $y_{r}^{w}$ across all regions in each state of nature: there exists a $y^{w}(s)$ such that

$$
y_{r}^{w}(s)=y^{w}(s)
$$

The planner is indifferent as to the regional split of fuel investment: global market clearance solely requires the sum of absolute regional investments to equate global fuel usage,

$$
\sum_{r} h_{r} z_{r}^{w}=f^{w}
$$


In the absence of climate damage, $D(f)=0$, the global planner's choices (18)-(20) are in line with the decentralized laissez-faire outcome (16). In presence of damages, comparison with the decentralized choices (13) and the market clearances (11) shows that the planner's fuel market activity choices are achieved by any set of taxes $\tau_{g}^{w}$ that together fully internalize the climate damage,

$$
\tau_{f}^{w}+\tau_{x}^{w}+\tau_{z}^{w}=D^{\prime}\left(f^{w}\right) \sum_{r} \omega_{r}
$$

This result was to be expected: Any given level of fuel usage involves the same global amount of resources being offered by deposit owners, extracted by investors, as well as finally consumed; globally, there is no substitution possible between these processes. Correspondingly, and in line with general principles of tax incidence, it is, in the present case of a global policy, irrelevant on which of the three activities the taxes are levied. ${ }^{6}$

The optimal taxes sum to the global marginal cost of the emission damage, in line with the Pigou principle for the internalization of externalities (Pigou, 1920): the policymaker imposes on the private actors the externalized social cost of their activities to avoid a net distortion. Annex $\mathrm{C}$ shows that this conclusion extends to the case where the investment options contain an alternative non-fuel asset with uncertain returns imperfectly correlated to those of the fuel projects.

The decreasing returns in the consumption utility $u$ warrant, for the here considered planner, who weights utilities equally across regions on a per-capita basis, a redistribution from regions better-off to those less well off, ensuring that for any given state of nature, consumption indexes are equated across regions, as formalized in (19). If the regions have equal endowments, as is implicitly assumed in the present analysis, this implies an offsetting via lump-sum transfers of any possible regional differences in conceived emission damage $\left(\omega_{r}\right)$. Furthermore, it requires inter-regional transfers to offset possible differences in per-capita investment levels. The stochasticity of the net payoff from extraction investment means that the latter transfers need to be contingent on the state of nature. It can be verified that if the planner was only allowed a deterministic transfer, the solution would set all regional investment choices to $z_{r}^{w}=f^{w}$.

\footnotetext{
${ }^{6}$ This assumes adequate redistributional transfers are possible. Under the assumption of homogenous endowments, such transfers are only warranted if the regional climate damage weights $\omega_{r}$ differ across regions.
} 


\section{Unilateral policy}

\subsection{Small open economy}

Let there be an active small open economy, region $a$, considering abatement, facing a passive, large remainder of the world, region $b$, that pursues a laissez-faire. We operationalize the small size of region $a$ compared to $b$ by assuming an arbitrarily large number $n, n \rightarrow \infty$, and defining sizes

$$
h_{a} \equiv n^{-1}, h_{b} \equiv 1-n^{-1}
$$

As we denote quantities in per-capita terms, the market clearances (11) rewrite

$$
f_{a}+(n-1) f_{b}=x_{a}+(n-1) x_{b}=z_{a}+(n-1) z_{b} .
$$

In the following the approximate sign, $\approx$, expresses that for the diverging size index $n \rightarrow \infty$, relations hold asymptotically with (at least) precision $o(1)$. Equalities, =, indicate faster convergence. We thus have $h_{a} \approx 0$ and $h_{b} \approx 1$. Together with the market clearance (22), this implies that asymptotically the three variables in the passive region are equal,

$$
f_{b} \approx x_{b} \approx z_{b}
$$

Regional utilities $y^{d}$ are continuous in the decision variables $f_{r}, x_{r}, z_{r}$. With (23), the decentralized behavior from (14) therefore implies that the activity levels of the agents in the non-abating region simplify asymptotically to

$$
\left[f_{b}, x_{b}, z_{b}\right] \alpha \sigma^{2} \approx v^{\prime}\left(f_{b}\right)-R c^{\prime}\left(x_{b}\right)
$$

Therefore, the region $b$ choices approach those of the global laissez-faire in (16),

$$
f_{b}, x_{b}, z_{b} \approx f^{l}
$$

and the absolute global consumption is asymptotically the same, $F \equiv \sum_{r} f_{r} \approx f^{l}$. The market prices become

$$
\begin{aligned}
& p=v^{\prime}\left(f_{b}\right) \approx v^{\prime}\left(f^{l}\right), \\
& q=c^{\prime}\left(x_{b}\right) \approx c^{\prime}\left(x^{l}\right) .
\end{aligned}
$$

The outcome described by (24)-(26) varies only marginally with choices in the small region $a$. Accordingly, planning in region $a$ takes prices $p$ and $q$ as given in the optimization. ${ }^{7}$ The problem of optimal regional behavior, maximizing the utility-value of the consumption

\footnotetext{
${ }^{7}$ Because the foreign region $b$ is large relative to $a$, this does not preclude relevant, price-related repercussions of region $a$ 's policy on the foreign consumption choice.
} 
index $y_{a}$ in (7), writes

$$
\begin{aligned}
& \max _{g_{a}} \mathrm{E}_{s}\left[u\left(v\left(f_{a}\right)-f_{a} p-R c\left(x_{a}\right)+R x_{a} q+z_{a}(p-R q-k(s))-\frac{\omega_{a}}{h_{a}} D(F)\right)\right] \\
& \text { subject to } F=\sum_{r} h_{r} f_{r}=\sum_{r} h_{r} x_{r}=\sum_{r} h_{r} z_{r} .
\end{aligned}
$$

Calculations analogous to those for the decentralized choices in section 3 show that the FOCs for the three activities yield

$$
\begin{aligned}
v^{\prime}\left(f_{a}\right) & \stackrel{!}{\approx} p+\omega_{a} D^{\prime}\left(f^{l}\right)\left(1+\partial\left[h_{b} f_{b}\right] / \partial\left[h_{a} f_{a}\right]\right), \\
R c^{\prime}\left(x_{a}\right) & \stackrel{!}{\approx} R q-\omega_{a} D^{\prime}\left(f^{l}\right)\left(1+\partial\left[h_{b} x_{b}\right] / \partial\left[h_{a} x_{a}\right]\right), \\
z_{a} \alpha \sigma^{2} & \stackrel{!}{\approx} p-R q-\omega_{a} D^{\prime}\left(f^{l}\right)\left(1+\partial\left[h_{b} z_{b}\right] / \partial\left[h_{a} z_{a}\right]\right) .
\end{aligned}
$$

The planner can align the domestic decentralized choices from (13) with these conditions using a set of activity-specific regional taxes $\tau_{g}^{u}$ given by

$$
\begin{aligned}
& \tau_{g}^{u} \equiv \omega_{a} D^{\prime}\left(f^{l}\right)\left(1-\mathrm{LR}_{g}\right) \\
& \text { for all } g \in\{f, x, z\}
\end{aligned}
$$

where $\mathrm{LR}_{g}$ denote activity-specific leakage rates: the absolute, offsetting reaction of foreign activity $g_{b}$ in response to the domestic absolute change in the level of region $a$ 's same activity, $g_{a}$, as follows,

$$
\begin{aligned}
& \mathrm{LR}_{g} \equiv-\partial\left[h_{b} g_{b}\right] / \partial\left[h_{a} g_{a}\right] \\
& \text { for all } g \in\{f, x, z\} .
\end{aligned}
$$

We will see that $\mathrm{LR}_{g}$ lie strictly between zero and one. For a unitary reduction of an activity $g$ by region $a$, holding the two other activity levels constant in $a$, the equilibrium effect on global emissions is thus a smaller but positive reduction, by $1-\mathrm{LR}_{g}$. Annex $\mathrm{B}$ identifies the leakage rates attached to exogenous reductions of region $a$ 's fuel use, resource offer, and fuel investment, respectively, applying Taylor expansions to the passive region's choices as function of the market prices, (13), and using market clearance conditions (11). The rates become

$$
\begin{aligned}
\mathrm{LR}_{f} & =\frac{-f^{\prime}(p)}{\left[R x^{\prime}(q)^{-1}+z^{\prime}(p-R q)^{-1}\right]^{-1}-f^{\prime}(p)}, \\
\mathrm{LR}_{x} & =\frac{R^{-1} x^{\prime}(q)}{R^{-1} x^{\prime}(q)+\left[z^{\prime}(p-R q)^{-1}-f^{\prime}(p)^{-1}\right]^{-1}}, \\
\mathrm{LR}_{z} & =\frac{z^{\prime}(p-R q)}{\left[R x^{\prime}(q)^{-1}-f^{\prime}(p)^{-1}\right]^{-1}+z^{\prime}(p-R q)} .
\end{aligned}
$$


Together with the price-responsiveness of the market activity levels, (15), we find

$$
\begin{aligned}
\mathrm{LR}_{f} & \approx \frac{-v^{\prime \prime}\left(f^{l}\right)^{-1}}{\left[c^{\prime \prime}\left(f^{l}\right) R+\alpha \sigma^{2}\right]^{-1}-v^{\prime \prime}\left(f^{l}\right)^{-1}} \in(0,1), \\
\mathrm{LR}_{x} & \approx \frac{\left[c^{\prime \prime}\left(f^{l}\right) R\right]^{-1}}{c^{\prime \prime}\left(f^{l}\right) R+\left[\alpha \sigma^{2}-v^{\prime \prime}\left(f^{l}\right)\right]^{-1}} \in(0,1), \\
\mathrm{LR}_{z} & \approx \frac{\left[\alpha \sigma^{2}\right]^{-1}}{\left[c^{\prime \prime}\left(f^{l}\right) R-v^{\prime \prime}\left(f^{l}\right)\right]^{-1}+\left[\alpha \sigma^{2}\right]^{-1}} \in(0,1) .
\end{aligned}
$$

To interpret these terms, consider the example of region $a$ 's unilateral reduction in fuel consumption $f_{a}$. Market clearances require, for region $b$ 's response to the reduction of $f_{a}$, the sum of

(i) the increase in region b's same activity, $f_{b}$, and

(ii) the simultaneous decrease of region $b$ 's other two activities, $x_{b}$ and $z_{b}$,

to equal region $a$ 's reduction of $f_{a}$. The proportion to which the reduction in $f_{a}$ is split between (i) and (ii) depends on the relative 'ease' with which the corresponding region $b$ changes take place. The ease by which fuel consumption - point (i) - reacts, is proportional to how strongly fuel consumption reacts to pressure (of a price change), $f^{\prime}(p)$. The ease by which resource offer and investment - point (ii) - simultaneously react, is proportional to the inverse of the sum of their 'resistances' to price changes, with 'resistances' as the inverse of the (time-adjusted) price-responsiveness of the considered activities, $R / x^{\prime}(q)$ and $1 / z^{\prime}(p-R q)$. Noting that the leakage rate is the share of reaction (i) in the overall foreign response $(\mathrm{i})+(\mathrm{ii})$, this explains the form of $\mathrm{LR}_{f}$ in (30). Interpretations of $\mathrm{LR}_{x}$ and $\mathrm{LR}_{z}$ are analogous.

Substituting these leakage rates allows rewriting the unilaterally optimal regional taxes (28) as

$$
\begin{aligned}
\tau_{f}^{u} & \approx \omega_{a} D^{\prime}\left(f^{l}\right) \frac{-v^{\prime \prime}\left(f^{l}\right)}{R c^{\prime \prime}\left(f^{l}\right)+\alpha \sigma^{2}-v^{\prime \prime}\left(f^{l}\right)}>0 \\
\tau_{x}^{u} & \approx \omega_{a} D^{\prime}\left(f^{l}\right) \frac{R c^{\prime \prime}\left(f^{l}\right)}{R c^{\prime \prime}\left(f^{l}\right)+\alpha \sigma^{2}-v^{\prime \prime}\left(f^{l}\right)}>0 \\
\tau_{z}^{u} & \approx \omega_{a} D^{\prime}\left(f^{l}\right) \frac{\alpha \sigma^{2}}{R c^{\prime \prime}\left(f^{l}\right)+\alpha \sigma^{2}-v^{\prime \prime}\left(f^{l}\right)}>0 .
\end{aligned}
$$

Each component individually falls short of the regional marginal disutility of emissions,

$$
0<\tau_{f}^{u}, \tau_{x}^{u}, \tau_{z}^{u}<\omega_{a} D^{\prime}\left(f^{l}\right)
$$

but together the three taxes sum up to this marginal emission disutility,

$$
\tau_{f}^{u}+\tau_{x}^{u}+\tau_{z}^{u}=\omega_{a} D^{\prime}\left(f^{l}\right)
$$


Annex $\mathrm{C}$ extends the analysis by adding to the investment menu a non-fuel asset with risky returns imperfectly correlated with those from fuel extraction. Leakage rates and optimal taxes found here apply with only minor changes.

For a global policy, the only criterion for optimal allocation is that the taxes on deposit sale, extraction investment, and fuel use sum to the relevant marginal damage, see (21). Here we see that unilateral taxation by the SOE, in contrast, warrants an individual tax for each of these three activities. It is easy to see by construction that the optimal tax on each activity does not depend on the tax levels really imposed by the region on the other activities. ${ }^{8}$ There is thus no natural substitutability between the individual unilateral taxes in the SOE, even though their optimal levels sum to the regionally perceived marginal emission damage. The tax value on each individual activity $g$ equals the Pigouvian tax scaled down by multiplication with $\left(1-\mathrm{LR}_{g}\right)$. This factor strictly between 0 and 1 is readily explained by the equilibrium effect of a unit of unilateral reduction in activity $g$ being only so much of global emission reduction.

The tax sum (33) extends Hoel's (1994) result of the regional taxes on supply and demand summing to the Pigouvian rate in a deterministic world without risky investment. While Hoel proposes an explanation why the optimal policy never subsidizes simultaneously the two activities he considered, there is also a natural explanation for all (here three, in Hoel two) taxes to total to the regionally perceived marginal climate damage: A simultaneous, unitary reduction of all three market activities in region $a$ does not affect the market conditions for $b$. Correspondingly such a change in $a$ will have a zero net leakage impact. In this absence of any overall leakage, the natural internalizing tax equals the marginal emission disutility, since a unitary reduction of all three activities implies a global emission reduction one-for-one, so full internalization of regionally perceived damage is warranted. Put differently: reducing all three domestic activity levels by one unit leaves the market conditions for actors in the remainder of the world unaffected, and thus does not induce any foreign behavioral response. As the global fuel use is therefore reduced by exactly one unit, we have one unit of global fuel consumption reduction opposing three times one unit of regional abatement when counting all regional activity changes individually; the sum of all leakage rates is $3-1=2$. Hence, $\sum_{g} L_{g}=2$, so that (28) yields $\sum_{g} \tau_{g}^{u}=\omega_{a} D^{\prime}\left(f^{l}\right)$.

The next section shows how these results extend to the case of a larger active region in a heterogeneous world, before 4.3 summarizes key observations from both cases.

\footnotetext{
${ }^{8}$ For each activity, the FOC used to derive the optimal tax directly yields the final tax terms we identified without interaction with the other taxes.
} 


\subsection{Large region, heterogeneous world}

Above we considered the optimal unilateral policy of an SOE in a world of regions homogenous in per-capita preferences and endowments. This had two key implications that may not always apply in reality:

1. Smallness idled terms-of-trade effects, as the small region had only a marginal effect on equilibrium prices.

2. Homogeneity of the countries implied essentially a balanced fuel sector absent climate policy: in a laissez-faire and in a given region, the level of resource supply, fuel consumption, and investment each took on the same value.

Here we consider a policy by a large region that cannot neglect its effect on terms-oftrade. The countries are heterogeneous so that they may be net importers or exporters in some fuel-market activities even absent climate policy. The following shows that the leakage rate and tax considerations above largely extend to the optimal unilateral policy of a larger region in a heterogeneous world, with the differences that

- terms-of-trade effects affect the optimal unilateral taxes, ${ }^{9}$ and,

- contrary to the case of the small country, a limitation of the regional policy to a subset of the three activities consumption, resource offer, and investment, affects the welfare-relevant leakage rates for the feasible policy and the optimal levels of the feasible taxes.

We have region-specific fuel utility and extraction costs, $v_{r}\left(f_{r}\right)$ and $c_{r}\left(x_{r}\right)$, and the maximization problem of (27) is now complicated by market prices varying with the region's choice,

$$
\begin{aligned}
& \max _{x_{a}, f_{a}, z_{a}} \mathrm{E}_{s}\left[u\left(v_{a}\left(f_{a}\right)-f_{a} p-R c_{a}\left(x_{a}\right)+R x_{a} q+z_{a}(p-R q-k(s))-\frac{\omega_{a}}{h_{a}} D(F)\right)\right] \\
& \text { subject to } F=\sum_{r} h_{r} f_{r}=\sum_{r} h_{r} x_{r}=\sum_{r} h_{r} z_{r} .
\end{aligned}
$$

We consider the CARA consumption utility $u$ from (10). ${ }^{10}$ In our joint optimization problem for the bundle $\left\{f_{a}, x_{a}, z_{a}\right\}$, the envelope theorem reduces complexity. Containing the planner's influence to a subset of the regional activities - for example, taxes may be politically feasible only for some of them - instead would complicate the analysis, as the

\footnotetext{
${ }^{9}$ In the case of symmetric countries all imposing the unilaterally optimal taxes there is no such termsof-trade effect as trade is balanced.

${ }^{10}$ Analysis and results remain qualitatively similar if we also regionalize the consumption utility $u$, using a region-specific risk-aversion $\alpha_{r}$ instead of the global value $\alpha$.
} 
effect of the choice of a given domestic activity level influences the decentralized choice of other domestic activities via global market prices. The first-order optimality conditions for the planner's joint optimization, with regrouped terms, become

$$
\begin{aligned}
v_{a}^{\prime}\left(f_{a}\right) & \stackrel{!}{=} p+\omega_{a} D^{\prime}(F)\left(1-\mathrm{LR}_{f}\right)+\left(f_{a}-z_{a}\right) \partial p / \partial f_{a}-\left(x_{a}-z_{a}\right) R \partial q / \partial f_{a} \\
R c_{a}^{\prime}\left(x_{a}\right) & \stackrel{!}{=} R q-\omega_{a} D^{\prime}(F)\left(1-\mathrm{LR}_{x}\right)-\left(f_{a}-z_{a}\right) \partial p / \partial x_{a}+\left(x_{a}-z_{a}\right) R \partial q / \partial x_{a} \\
z_{a} \alpha \sigma^{2} & \stackrel{!}{=} p-R q-\omega_{a} D^{\prime}(F)\left(1-\mathrm{LR}_{z}\right)-\left(f_{a}-z_{a}\right) \partial p / \partial z_{a}+\left(x_{a}-z_{a}\right) R \partial q / \partial z_{a}
\end{aligned}
$$

In contrast, decentralized agents who maximize personal payoffs, taking prices and climate damages as given in (34) and accounting for taxes to be paid, act according to the private indifference conditions (13). Comparing these private choices to the planner's choices (35), we find the regional optimum implemented by taxes of the level

$$
\begin{aligned}
\tau_{f}^{U} & =\omega_{a} D^{\prime}(F)\left(1-\mathrm{LR}_{f}\right)+\left(f_{a}-z_{a}\right) \partial p / \partial f_{a}-\left(x_{a}-z_{a}\right) R \partial q / \partial f_{a}, \\
\tau_{x}^{U} & =\omega_{a} D^{\prime}(F)\left(1-\mathrm{LR}_{x}\right)+\left(f_{a}-z_{a}\right) \partial p / \partial x_{a}-\left(x_{a}-z_{a}\right) R \partial q / \partial x_{a}, \\
\tau_{z}^{U} & =\underbrace{\omega_{a} D^{\prime}(F)\left(1-\mathrm{LR}_{z}\right)}_{\text {climate }}+\underbrace{\left(f_{a}-z_{a}\right) \partial p / \partial z_{a}}_{\text {lamage }}-\underbrace{\left(f_{a}-z_{a}\right) R \partial q / \partial z_{a}}_{\text {terms-of-trade }},
\end{aligned}
$$

with leakage rates $\mathrm{LR}_{g}$ as defined in (29). Without particular assumptions about the magnitudes of the second derivatives of consumption utilities and extraction costs, $v_{r}^{\prime \prime}<0$ and $c_{r}^{\prime \prime}>0$, the directions of the net effects of the price reactivity terms, $\frac{\partial p}{\partial g_{a}}$ and $\frac{\partial q}{\partial g_{a}}$, $g=\{f, x, z\}$, remain ambiguous. They depend on the balance between the effect of the taxes on the equilibrium levels of $f_{a}, x_{a}, z_{a}$, more precisely of consumption net of investment, $f_{a}-z_{a}$, and deposit supply net of investment, $x_{a}-z_{a}$. Taxes are positive if climate effects dominate, but individual tax levels can become negative in presence of large terms-of-trade effects and limited climate concern or strong leakage effects.

The leakage analysis in Annex B applies, using the passive region's functions $v_{b}$ and $c_{b}$ : For any equilibrium with given activity levels in the active region, $f_{a}, x_{a}$ and $z_{a}$, marginal changes in region $a$ are subject to leakage rates of the same form as for the SOE, (31), evaluated for the passive region's parameters. We write $v_{b}^{\prime \prime}$ and $c_{b}^{\prime \prime}$ for $v_{b}^{\prime \prime}\left(f_{b}\right)$ and $c_{b}^{\prime \prime}\left(x_{b}\right)$, so we have

$$
\mathrm{LR}_{f}=\frac{c_{b}^{\prime \prime} R+\alpha \sigma^{2}}{c_{b}^{\prime \prime} R+\alpha \sigma^{2}-v_{b}^{\prime \prime}}, \quad \operatorname{LR}_{x}=\frac{\alpha \sigma^{2}-v_{b}^{\prime \prime}}{c_{b}^{\prime \prime} R+\alpha \sigma^{2}-v_{b}^{\prime \prime}}, \quad \mathrm{LR}_{z}=\frac{c_{b}^{\prime \prime} R-v_{b}^{\prime \prime}}{c_{b}^{\prime \prime} R+\alpha \sigma^{2}-v_{b}^{\prime \prime}} .
$$

The leakage components of the optimal taxes (36) thus do not directly depend on the relative size of the two regions. This means, for example, that assuming balanced net trade positions in all three fuel-related activities before the implementation of taxes, for a small enough damage and hence implied tax, there is no significant difference between 
the leakage rate in the case where, compared to the active region, the remainder of the world is large or small.

To identify the price reactions, we use market-clearance conditions and similar Taylor approximations of foreign responses to unilateral activity changes as for the leakage rates, yielding (B.11) in Annex B. We find

$$
\begin{aligned}
\frac{\partial p}{\partial f_{a}} & =-\frac{h_{a}}{h_{b}} \frac{1}{f_{b}^{\prime}} \frac{\frac{R}{x_{b}^{\prime}}+\frac{1}{z^{\prime}}}{\frac{R}{x_{b}^{\prime}}+\frac{1}{z^{\prime}}-\frac{1}{f_{b}^{\prime}}}, & \frac{\partial q}{\partial f_{a}} & =-\frac{h_{a}}{h_{b}} \frac{1}{x_{b}^{\prime}} \frac{\frac{1}{f_{b}^{\prime}}}{\frac{R}{x_{b}^{\prime}}+\frac{1}{z^{\prime}}-\frac{1}{f_{b}^{\prime}}}, \\
\frac{\partial p}{\partial x_{a}} & =\frac{h_{a}}{h_{b}} \frac{1}{f_{b}^{\prime}} \frac{\frac{R}{x_{b}^{\prime}}}{\frac{R}{x_{b}^{\prime}}+\frac{1}{z^{\prime}}-\frac{1}{f_{b}^{\prime}}}, & \frac{\partial q}{\partial x_{a}} & =-\frac{h_{a}}{h_{b}} \frac{1}{x_{b}^{\prime}} \frac{\frac{1}{z^{\prime}}-\frac{1}{f_{b}^{\prime}}}{\frac{R}{x_{b}^{\prime}}+\frac{1}{z^{\prime}}-\frac{1}{f_{b}^{\prime}}}, \\
\frac{\partial p}{\partial z_{a}} & =\frac{h_{a}}{h_{b}} \frac{1}{f_{b}^{\prime}} \frac{\frac{1}{z^{\prime}}}{\frac{R}{x_{b}^{\prime}}+\frac{1}{z^{\prime}}-\frac{1}{f_{b}^{\prime}}}, & \frac{\partial q}{\partial z_{a}} & =\frac{h_{a}}{h_{b}} \frac{1}{x_{b}^{\prime}} \frac{\frac{1}{z^{\prime}}}{\frac{R}{x_{b}^{\prime}}+\frac{1}{z^{\prime}}-\frac{1}{f_{b}^{\prime}}},
\end{aligned}
$$

where $x_{b}^{\prime}, z^{\prime}$ and $f_{b}^{\prime}$ stand for $x_{b}^{\prime}(q), z^{\prime}(p-R q)$, and $f_{b}^{\prime}(p)$ respectively. Using the slopes (15), the price-reactions rewrite

$$
\begin{aligned}
\frac{\partial p}{\partial f_{a}} & =-\frac{h_{a}}{h_{b}} v_{b}^{\prime \prime} \frac{R c_{b}^{\prime \prime}+\alpha \sigma^{2}}{R c_{b}^{\prime \prime}+\alpha \sigma^{2}-v_{b}^{\prime \prime}}, & \frac{\partial q}{\partial f_{a}} & =-\frac{h_{a}}{h_{b}} c_{b}^{\prime \prime} \frac{v_{b}^{\prime \prime}}{R c_{b}^{\prime \prime}+\alpha \sigma^{2}-v_{b}^{\prime \prime}}, \\
\frac{\partial p}{\partial x_{a}} & =\frac{h_{a}}{h_{b}} v_{b}^{\prime \prime} \frac{R c_{b}^{\prime \prime}}{R c_{b}^{\prime \prime}+\alpha \sigma^{2}-v_{b}^{\prime \prime}}, & \frac{\partial q}{\partial x_{a}} & =-\frac{h_{a}}{h_{b}} c_{b}^{\prime \prime} \frac{\alpha \sigma^{2}-v_{b}^{\prime \prime}}{R c_{b}^{\prime \prime}+\alpha \sigma^{2}-v_{b}^{\prime \prime}}, \\
\frac{\partial p}{\partial z_{a}} & =\frac{h_{a}}{h_{b}} v_{b}^{\prime \prime} \frac{\alpha \sigma^{2}}{R c_{b}^{\prime \prime}+\alpha \sigma^{2}-v_{b}^{\prime \prime}}, & \frac{\partial q}{\partial z_{a}} & =\frac{h_{a}}{h_{b}} c_{b}^{\prime \prime} \frac{\alpha \sigma^{2}}{R c_{b}^{\prime \prime}+\alpha \sigma^{2}-v_{b}^{\prime \prime}} .
\end{aligned}
$$

Substituting in the leakage rates and price-reaction in the tax expressions (36) yields the optimal tax expressions

$$
\begin{aligned}
\tau_{f}^{U} & =\frac{-v_{b}^{\prime \prime}}{c_{b}^{\prime \prime} R+\alpha \sigma^{2}-v_{b}^{\prime \prime}}\left[\omega_{a} D^{\prime}(F)+\frac{h_{a}}{h_{b}}\left[\left(f_{a}-z_{a}\right)\left(c_{b}^{\prime \prime} R+\alpha \sigma^{2}\right)-\left(x_{a}-z_{a}\right) c_{b}^{\prime \prime} R\right]\right], \\
\tau_{x}^{U} & =\frac{c_{b}^{\prime \prime} R}{c_{b}^{\prime \prime} R+\alpha \sigma^{2}-v_{b}^{\prime \prime}}\left[\omega_{a} D^{\prime}(F)+\frac{h_{a}}{h_{b}}\left[\left(f_{a}-z_{a}\right) v_{b}^{\prime \prime}+\left(x_{a}-z_{a}\right)\left(\alpha \sigma^{2}-v_{b}^{\prime \prime}\right)\right]\right], \\
\tau_{z}^{U} & =\frac{\alpha \sigma^{2}}{c_{b}^{\prime \prime} R+\alpha \sigma^{2}-v_{b}^{\prime \prime}}\left[\omega_{a} D^{\prime}(F)+\frac{h_{a}}{h_{b}}\left[\left(f_{a}-z_{a}\right) v_{b}^{\prime \prime}-\left(x_{a}-z_{a}\right) c_{b}^{\prime \prime} R\right]\right] .
\end{aligned}
$$

These are similar to the taxes $\tau_{g}^{u}$ for the SOE, but with adjustment for terms-of-trade effects and regionalized fuel demand and resource supply functions. Like in the case of the SOE, the taxes sum to the regionally perceived marginal climate damage,

$$
\tau_{f}^{U}+\tau_{x}^{U}+\tau_{z}^{U}=\omega_{a} D^{\prime}(F)
$$

with the above intuition about the neutrality of a simultaneous change of all market activities still applying for the effect on foreign emissions, and extending to the terms-oftrade effect: if the policy region changes all three market activities by the same amount, 
the net effect on global equilibrium prices is nil, and accordingly such a change warrants no terms-of-trade related policy adjustments.

\subsection{Observations}

Key conclusions about the optimal unilateral taxes found for the small open economy, (32), and the large open economy, (38), as well as about the corresponding leakage rates, (31) and (37), are:

1. Tax all activities. Optimal unilateral climate taxation ought not to be limited to consumption taxes. Instead, taxes should also be imposed on deposit sales within the region, and - as investment is risky - equally on regional funds invested for extraction worldwide. The reluctance of foreign investors to build up excessive investments in the risky fuel sector limits divestment leakage to a level below $100 \%$, so that unilateral divestment (as purely personal choice, or incentivized through investment taxes) is not in vain. Unilateral taxation remains second-best; only a global tax - which, as shown in section 3.3, can be levied on either of the three activities - can implement the first-best.

2. Without uncertainty, investment tax is useless but also costless. Without uncertainty, investment leakage jumps to $100 \%, \mathrm{LR}_{z}=1$, as there are no risk-concerns preventing third party investors to fully offset funds withheld by the active divestor. A small tax suffices to shift all domestic investments to non-fuel assets. From a welfare perspective, such a tax is useless, but it also comes without cost: the cost attached to withdrawing (taxing) fossil fuel investments by a subset of investors is nil for any interior solution on a deterministic fuel market: A no-arbitrage condition from competitive investments in the foreign region implies that the equilibrium investment return equals the return $R$ of alternative assets; a fuel investment change by a given subset of agents is fully negated by offsetting reactions from indifferent investors.

3. Optimal taxes sum to the Pigouvian. The sum of the optimal unilateral taxes on all activities always equals the perceived marginal climate damage, $\sum_{g} \tau_{g}^{u}=\omega_{a} D^{\prime}(F)$, both, for the SOE as well as for a large economy. The intuition is simple: Reducing all three activities by one unit simultaneously reduces global fuel use by one unit, but does not impact the behavior of the rest of the world, and thus neither terms-of-trade. The incentive for such a simultaneous reduction thus corresponds to the level of the simple Pigouvian internalizing tax based on the level of domestically perceived damage. ${ }^{11}$

4. Size-independent leakage rates. As the size of the active country becomes small, the leakage rates neither approach zero, nor $100 \%$. Instead, they remain at levels strictly

\footnotetext{
${ }^{11}$ The climate concern weight of the active region, $\omega_{a}$, may contain an element reflecting altruistic concern about climate damages born by other regions. For the case of an SOE, this is a necessary condition for the absolute weight $\omega_{a}$ not to collapse to zero, i.e., for domestic taxes to be non-marginal.
} 
within the interior of the interval between 0 and 1, non-marginally different from these bounds. Divestment activity by any actor thus can be expected to lead to non-zero global emission reductions.

5. Tax low (foreign) elasticities, tax high risk. The results imply that optimal unilateral tax levels are high on activities where foreign price-responsiveness is small, or where risk is high (which also yields a low price-responsiveness of the risky activity). With some parallels to the Ramsey (1927) principle of taxing goods inversely proportional to demand-elasticities in order to contain costly avoidance, the results here are explained by the attempt to contain climate costs from foreign response (leakage) to the domestic taxes. The foreign fuel demand and supply curves, as well as the investment risk factor $\alpha \sigma^{2}$ therefore determine for which measure the leakage rate is highest and the tax thus lowest. A relatively high demand elasticity, $\left|v^{\prime \prime}\left(f_{b}\right)\right| \ll\left[c^{\prime \prime}\left(x_{b}\right), \alpha \sigma^{2}\right]$, yields a demand leakage rate close to 1 but low leakage from unilateral supply and investment withdrawals. Correspondingly, the tax on fuel consumption will be low and the unilateral policy should instead focus on taxes on deposit supply and extraction investment. A relatively high deposit supply elasticity, $c^{\prime \prime}\left(x_{b}\right) \ll\left[\left|v^{\prime \prime}\left(f_{b}\right)\right|, \alpha \sigma^{2}\right]$, yields a supply leakage rate close to 1 but low leakage from unilateral demand and investment reductions. Finally, for a relatively low investment risk penalty, $\alpha \sigma^{2} \ll\left[\left|v^{\prime \prime}\left(f_{b}\right)\right|, c^{\prime \prime}\left(x_{b}\right)\right]$, the investment leakage rate is close to 1 , but leakage from unilateral demand and supply reductions is low.

The intuition in detail: If, for example, demand reacts strongly to the fuel price, a consumption reduction by some is readily compensated by others' consumption increase in response to an induced equilibrium fuel market price reduction, so a high demand side leakage rate obtains. The high demand elasticity however also means that a reduction in the fuel offer by some cannot easily be compensated by supply from additional foreign reserves as these would have higher fuel costs that the price-elastic consumers are not willing to bear, so a low supply side leakage rate obtains. Conversely, with a high supply elasticity, withholding resources by some just means there is ample supplemental supply to make up for the 'unilateral' reduction; a high supply side leakage rate. It means also a low reaction of equilibrium prices in response to a unilateral fuel consumption reduction, leading to a low demand side leakage rate.

These observations are in line with Bohm's (1993) finding of a domestic consumption reduction to be fruitful mainly with a relatively low demand elasticity, and a supply reduction instead with a relatively low supply elasticity.

6. Infinitely great benefit-cost ratio for first units divested. The regional perunit cost of reducing any of the three fuel activities to below the level regionally optimal when ignoring climate change - equivalent to marginally increasing the taxes from the level optimal without climate concerns i.e. when $\omega_{a}=0-$, is marginal even if climate benefits are ignored. As the leakage rates remain non-marginally below $100 \%$, these first 
units of unilateral activity reduction yield a very good (initially infinite) benefit-cost ratio in terms of climate-benefit per unit of non-climate cost. For carbon divestment, this means a divestor can adjust her portfolio at least to some degree to reflect her climate concerns without fearing any unjustifiable divestment costs. Only when the divestment (or, equivalently, tax) reaches a substantial level, ${ }^{12}$ can marginal or total divestment costs become substantial before climate benefits are accounted.

We have assumed a handling cost $k$ homogenous across resource units. Annex D shows how the analysis extends to costs imperfectly correlated across deposits.

\section{Discussion}

\subsection{Divestment by individual or institutional investor}

The investment tax $\tau_{z}^{u}$ in (32) suggests a regional population with concern for the climate wants to impose a positive unilateral tax on fossil fuel investments by domestic persons or institutions, even if leakage-concerns limit the optimal level of this tax. Standard carbon taxes alike, the investment tax is a soft measure, allowing actors to remain invested in the sector if they deem gains to outweigh the internalized costs. Individual investors will thus have the chance to reduce their fuel investments to a level at which the risk-adjusted excess gross return justifies paying the investment tax; that may mean full or only partial divestment by the concerned actors.

Such genuine carbon divestment taxes do not exist, but a global divestment movement is gaining traction, with, for example, the world's largest sovereign wealth fund, as well as numerous large university and city funds, and private foundations having enacted rules about avoidance of fossil-fuel related investments (Reuters, 2015; for a list of withdrawing institutions, cf. Fossil Free, 2015). The model studied here considers investment taxes, but the application to the question of whether or how individuals concerned by climate change may want to adjust investment portfolios, is straightforward. The SOE considered above can equally be thought of as an individual private or institutional investor. It is irrelevant that, unlike in the model, this market participant may not itself be a significant fuel consumer or resource deposit supplier. In practice, the here identified ideal 'tax' will not typically be imposed in the concerned investor's accounting. Instead, the level of the tax pinned down in (32) shows how strongly a rational investor with a taste $(\omega)$ for global climate protection (relative to capital gain) tries to avoid fuel assets; what additional shadow cost she will attach to her marginal fuel investment. The particular place of fossil fuel assets in her portfolio will decide whether the climate dis-benefit implicitly to be

\footnotetext{
${ }^{12}$ Relative to the active agent's own investment.
} 
accounted for at the level of the investment $\operatorname{tax} \tau_{z}^{u}$ warrants only a reduction of the share of fuel assets in her portfolio, or her full divestment instead.

\subsection{Divestment: neither miracle, nor completely without direct impact}

When financial investors chose their portfolios, they seek to maximize their expected payoff. For risk-averse actors, this implies trading-off expected value and variability of the earned return. Diversification within and across various sectors and financial product types can help to contain risk (return variability), while still achieving an adequate average return. Fossil fuel investment projects seem to be subject to substantial sector-specific risks in the short- and medium-term (cf. Figure 1). This may partly be explained by the slow price-response of physical quantities on both market sides, demand and supply. On one hand, exploration and commencement of extraction typically require years of preparation and high capital outlays, and once the production infrastructure in place, fuels can be extracted at limited costs for years (cf., e.g., Venables, 2011). On the other hand, habits, infrastructure and contractual arrangements, as well as the lack of readily available substitutes, lock in fuel consumption patterns. The low (or slow) price-responses on both sides of the clearing market means small deviations from anticipated quantities on either side can entail soaring or plummeting prices. This sector-specific risk, diversification against which may not be easy, can be compensated by a high expected return in the sector in a market equilibrium. All else equal, it warrants for risk-averse portfolio investors to allocate a positive but limited share of capital in the sector. And it explains the claim of substantial private economic costs of an exclusion of fuel investment from the portfolio of large investors (cf., e.g., the case of the largest university funds under pressure to divest: Faust, 2013; Stavins, 2013).

The presented framework captures the motive of return maximization and how it is traded off against risk minimization, leading individual investors to allocate parts of their funds to the fuel sector and the rest to alternative investments. Opponents of carbon divestment measures emphasize how unilateral divestment would merely lead to a substitution of funds by third parties with no (or insignificant) repercussions on greenhouse-gas emissions, but they equally insist on the divestors to bear significant economic losses, affecting rates

of return (e.g., Faust, 2013; Will, 2015; Washington Post, 2013; Stavins, 2013). The present analysis suggests that the two claims are incompatible. Both, climate benefits and private costs from divestment - from individual actors or from entire regions - are inherently linked to the risk-premium on investments into the sector. If this risk-premium is small, fuel divestment has minimal costs - fuel assets are substituted with alternative assets without significant costs - and indeed little environmental benefit, as third parties 
elsewhere in the world offset the divested funds as readily as the divestor was able to withdraw them. With a large premium, fuel investors may bear a non-negligible cost when they actively withdraw all their funds from the fuel sector, but our analysis suggests that in this case, the divestment also has non-marginal financial net repercussions for the fuel-extractive sector. As shown here, under standard conditions this can be expected to lead to a reduction of the total amount of fuel extracted.

\subsection{Investment tax: delineation and relocation}

Cynics might denounce a unilateral investment tax as futile for practical reasons, pointing out difficulties of delineation and evasion (relocation) related to the imposition of financial investment or transaction taxes. Two particular issues stand out for carbon investment taxes:

1. Financial vehicles and investments are complex and it could be difficult to effectively delineate by written law which transactions are to be covered how by the tax.

2. More easily than domestic fuel consumption and deposit supply, relocation of which involved moving physical activities, financial transactions can be shifted to unaffected marketplaces, largely without movement of physical persons or real capital.

Such issues may indeed represent a burden for the effectiveness of an investment tax, especially if imposed by a small region. Empirical evidence from fuel divestment taxes seems nonexistent. Very similar issues are, however, typically related to stamp duties, general financial transaction taxes, and Tobin taxes, or financial boycott measures. For these types of investment taxes, theoretic studies and available empirical evidence provide some insight.

A detailed discussion of arguments and experience with such related financial measures is beyond the scope of this paper. Two examples - however different from to the case of possible fuel investment taxes - may nevertheless be valuable as a testimony that at least in some cases, such measures may turn out to be more realistic than one might think on first sight. First, experience with unilateral stamp duties in various countries, including United Kingdom, Austria, Greece, Poland, Portugal, Spain, Switzerland, Cyprus, China, and Singapore, suggests that avoidance measures by market participants need not always be overwhelming, even in the case where the financial transaction tax is implemented unilaterally, and if it amounts to a substantial level. Second, the arguably dramatic effects of the Western sanctions notably on Russian fuel firms in response to the Crimea Crisis further may be a sign that, if political will exists, effective delineation between different types of investments can be practically feasible, even with very limited time at disposal. 


\subsection{Time consistent policy}

We have considered a committed policy, with timing relevant only for discounting. Giving up the implicit assumption of a government able to commit in period 1 to a consumption tax in period 2, the effect of requiring the tax to be subgame perfect is straightforward in the case of a regionally constrained government: Investors lock in their investments, and thus the level of extraction, in period 1. Market clearance means all extracted fuel will be consumed in period $2,{ }^{13}$ independently of the consumption tax level. So, seen from period 2, a consumption tax, which implies a distortionary cost on domestic consumers to the benefit of foreign consumers, has costs without any benefit - leakage of $100 \%-$, and is thus to be avoided. While the optimal consumption tax become nil in this case, the SOE's regionally optimal deposit and investment taxes, which can be levied in period 1, remain unchanged. For a large open economy matters become more complicated when commitment is not possible. The period 1 taxes on investment and extraction affect the domestic consumption which is not anymore under direct policy control. This effect is reflected in the optimal subgame-perfect taxes, which therefore depend on the domestic demand elasticity.

In the case of a global policy, the impossibility to commit necessitates that the government shifts all taxes to period 1, as producers anticipate that the policymaker will have no incentive to impose any consumption tax once fuels are extracted. ${ }^{14}$ Besides this shift, the time-consistency problem has no implication for the global optimum in our framework; it suffices for the policymaker to levy taxes on the activities it can theoretically tax in period 1 already, i.e., deposit supply and investment, at levels that in total sum up to the Pigouvian tax level (Pigou, 1920).

\subsection{Further aspects}

The analysis abstracts from key intertemporal aspects. Dynamic studies of demand-side measures in a framework with progressive exhaustion of fossil fuels and accumulation of emissions over time suggest that unilaterally optimal, committed carbon taxes are proportional to leakage rates that take into account the intertemporal path of foreign offsetting. The relevant climate damage is the net-present-value of current and future implied emission damages (e.g. Edenhofer and Kalkuhl 2010; Hoel 2011; Habermacher, 2015). This seems a natural refinement of results from the the static analysis here. However, the dynamics lead to complications that cannot be captured in the static framework. Optimal dynamic tax paths are not generally time-consistent, so that if policy-makers cannot

\footnotetext{
${ }^{13}$ We assume an interior solution, i.e., a damage too low to incentivize the policymaker to levy a tax high enough for the fuel supply-price to become zero.

${ }^{14}$ Though the government could use the demand tax to extract rents without efficiency costs.
} 
commit to stick forever to the tax path optimal from today's perspective, a second-best, time-consistent policy may be the best that is achievable (cf., e.g., Karp, 1984). Furthermore, a green paradox could arise if realistically climate taxes can be phased in only gradually: fuel owners anticipate that stringent policy reduces the value of future sales and thus shift sales to early periods when the tax is still suboptimally low (e.g., Sinn, 2008; Hoel, 2010; van der Ploeg and Withagen, 2010; Habermacher and Kirchgässner, 2011; Pittel et al., 2014). In extreme cases the policy may thus accelerate rather than delay fuel consumption overall. This could extend to divestment; if a gradually emerging divestment movement or tax progressively increases financial pressure, some owners might try to sell their resources early before the value is impacted; the divestment movement as a whole could have unintended consequences.

We consider a single fuel. In reality, there exist a host of fossil fuels and deposits strongly heterogeneous along a multitude of dimensions and linked with a complex pattern of shorter- and longer-term substitutabilities that could lead to counterintuitive effects. For example, fossil energy from expensive gas, and to a lesser degree from oil, is much less carbon intensive than coal, so that investment into the former two could be beneficial for the climate if they are used to displace abundant coal. Correspondingly, divestment from prominent oil and gas focused fossil fuel firms could backfire.

We further analyze a stylized fossil fuel investment sector, accounting for the trade-off between expected return maximization and risk containment, but abstracting from transaction costs, incomplete markets, imperfect information of market participants with diverging views about profitability, or heterogeneity in risk preferences and investment horizons. Presuming interior solutions further means we focus on the intensive margin of investment (how much investors invest in the fuel sector) but do not explicitly discuss the extensive margin (decisions whether investors invest in fuels). It would be interesting to see in future research, how these issues impact the key results found here. We assume a risky cost component with a simple correlation across deposits. This can be seen as a proxy to the arguably overwhelming global market-price related risk for example for oil. Considering additional depot-specific risks, as well as regional market-price related risks for mainly regionally traded fuels such as natural gas seems interesting.

We study the option of divestment with the aim of affecting fuel extraction. Alternatively, climate-concerned parties could invest into fossil fuel deposits exactly for the purpose of ensuring these deposits remain untapped. Harstad (2012) studies this possibility and suggests that buying marginal reserves to keep them underground could be an efficient unilateral climate protection measure; Eichner and Pethig (2015) discuss in which cases these results could be realistic, and environmental protection groups start thinking about practical ways to implement such measures (e.g. Bloomberg, 2015). It is unclear whether such invest-to-not-extract measures could, from a practical perspective, ever contribute 
significantly to fuel usage reduction. As Bohm (1993) speculates, there may be quite small a volume of relevant deposits that can be bought from foreign governments or so for realistic, eternal non-use.

Habermacher (2014) raises the question whether divestment could backfire from a geopolitical point of view. If the most climate-concerned regions are actively divesting from fossil fuels, the remainder of the world is able to profiteer from lucrative fossil fuel investment possibilities. This additional profit on fuel markets could leave the climate laggards even less willing to partake in global climate agreements that are so urgently needed for a realistic chance to contain climate change to a reasonable level.

The present analysis abstracts from energy-intensive traded goods. Literature suggests that concern for global emissions warrants a tariff on the regional consumption of imported goods, and possibly a tax rebate on goods to be exported (e.g., Böhringer et al., 2010). Integration of such concerns could valuably extend the present analysis.

\section{Conclusion}

Countries interested in reducing global greenhouse gas emissions often resort to domestic fuel consumption reductions. In addition, they can limit the domestic supply of resources, which lifts global fuel market prices. The present analysis shows that, if fuel extraction and transformation projects have uncertain returns, the financial markets offer a third option for a region to unilaterally impact the global fuel use. By limiting the regional funds flowing into the fuel market, a region can reduce the capital flowing into the sector globally, increasing the equilibrium fuel consumer price even when the foreign investors' response is accounted for. This result appears to be robust to a variety of assumptions. The unilaterally acting region can be as small as an individual actor that considers 'divesting', or it can constitute a large share of the global economy. The extraction costs may be perfectly correlated across fields or there may be many fields with imperfectly correlated costs. The fuel market investments may be an alternative to a simple, riskless asset with a lower expected return, or there may in addition be alternative, risky assets whose returns are imperfectly correlated to the fuel-market returns.

All three elements of the unilateral policy - taxes on fuel consumption, on resource deposit supply, and on unilateral investments into the global extraction market - are subject to leakage: Reduction in either of the three activities by domestic agents is partly offset by increases in the same activity abroad. We show how the expected offset relates to the shape of the fuel demand and resource supply curves, as well as to risk-aversion and return uncertainty, and we find expressions for the optimal taxes on the three activities, taking into account this foreign response. 


\section{References}

Bloomberg (2015), Greenpeace Says Can Find Cash to Buy Vattenfall Coal Assets, http://www.bloomberg.com/news/articles/2015-10-06/ greenpeace-says-it-can-find-cash-to-buy-vattenfall-coal-assets (accessed 2015-12-21).

P. Boнm (1993), Incomplete International Cooperation to Reduce CO2 Emissions: Alternative Policies, Journal of Environmentla Economics and Management 24(3), pp. $258-271$.

C. Böhringer, A. Lange And T.F. Rutherford (2010), Optimal Emission Pricing in the Presence of International Spillovers: Decomposing Leakage and Terms-of-Trade Motives, NBER Working Paper No. 15899, Cambridge MA, April.

Ph.J. Crabbé (1982), Sources and Types of Uncertainty, Information and Control in Stochastic Economic Models of Non-Renewable Resources, in G.Feichtinger (ed.), Optimal Control Theory and Economic Analysis, pp. 185 - 208.

P. Dasgupta and G. Heal (1974), The Optimal Depletion of Exhaustible Resources, The Review of Economic Studies 41, pp. 3 - 28.

P. Dasgupta And J.E. Stiglitz (1976), Uncertainty and the Rate of Extraction under Alternative Institutional Arrangements, Institute for Mathematical Studies in the Social Sciences, Technical Report No. 179.

O. Edenhofer And M. Kalkuhl (2010), Prices vs. Quantities and the Intertemporal Dynamics of the Climate Rent, CESifo Working Paper No. 3044, Munich, May.

Th. Eichner And R. Pethig (2015), Buy Coal to Mitigate Climate Damage and Benefit from Strategic Action!, Paper Presented at the CESifo Area Conference 2015 on Energy and Climate Economics, October. See also: http://www.webmeets.com/ files/papers/eaere/2015/188/Eichner\%20-\%20Pethig\%20EAERE\%202015. pdf (accessed 2015-12-21).

D. Faust (2013), Fossil Fuel Divestment Statement, Harvard University Office of the President 3 Oct 2013, http://www.harvard.edu/president/fossil-fuels (accesed 2015-06-05).

FossiL Free (2015), Divestment Commitments, http://gofossilfree.org/ commitments/ (accessed 2015-07-08).

R. Golombek, C. Hagem and M. Hoel (1995), Efficient Incomplete International Climate Agreements, Resource and Energy Economics 17(1), pp. 25 - 46.

F. Habermacher (2014), Carbon Divestment as a Rational Climate Protection Measure?, 15th Global Conference on Environmental Taxation (GCET) 24-25.9.2014, Aarhus University, Denmark. http://conferences.au.dk/fileadmin/conferences/ gcet/Presentations_in_the_detailed_programme/I_003_presentation_ DivestmentGCET_25Sep2014_Habermacher.pdf. 
F. Habermacher (2015), Carbon Leakage: A Medium-and Long-Term View, No. 5216, Munich, February.

F. Habermacher and G. Kirchgässner (2011), Climate Effects of Carbon Taxes, Taking into Account Possible Other Future Climate Measures, CESifo Working Paper No. 3404, Munich, March.

B. Harstad (2012), Buy Coal! A Case for Supply-Side Environmental Policy, Journal of Political Economy 120(1), pp. $77-115$.

O.C. Herfindahl (1967), Depletion and Economic Theory, in M.H.Gaffney (ed.), Extractive Resources and Taxation, pp. $63-69$.

M. Hoel (1978), Resource Extraction when a Future Substitute has an Uncertain Cost, The Review of Economic Studies 45(3), pp. 637 - 644.

M. Hoel (1994), Efficient Climate Policy in the Presence of Free Riders, Journal of Environmental Economics and Management 27(3), pp. 259 - 274.

M. Hoel (2010), Is there a Green Paradox?, CESifo Working Paper No. 3168, Munich, September.

M. Hoel (2011), The Supply Side of CO2 with Country Heterogeneity, The Scandinavian Journal of Economics 113(4), pp. 846 - 865.

L. KARP (1984), Optimality and Consistency in a Differential Game with Non-Renewable Resources, Journal of Economic Dynamics and Control 8, pp. 73 - 97.

A.C. Pigou (1920), The Economics of Welfare, New York.

K. Pittel, R. van der Ploeg and C. Withagen (2014), Climate Policy and Exhaustible Resources - The Green Paradox and Beyond, MIT Press.

Washington Post (2013), For Institutional Investors, No Ditching of Fossil Fuels Yet, 30 Nov 2013, http://www.washingtonpost.com/opinions/ for-institutional-investors-no-ditching-fossil-fuels-yet/2013/11/30/ c1ffbcec-579e-11e3-835d-e7173847c7cc_story.html (accessed 2015-06-05).

F.P. Ramsey (1927), A Contribution to the Theory of Taxation, The Economic Journal, $37(145)$, pp. $47-61$.

Reuters (2015), Norway Parliament Votes to Cut Coal Investments, Reuters, http: //www.reuters.com/article/2015/06/05/idUSL5NOYR2WP20150605 (accessed 201506-05).

H.W. Sinn (2008), Public Policies Against Global Warming: A Supply Side Approach, International Tax and Public Finance 15(4), pp. 360 - 394.

R. Stavins (2013), Climate Change, Public Policy, and the University, An Economic View of the Environment, 22 Oct 2013, http://www.robertstavinsblog. org/2013/10/22/climate-change-public-policy-and-the-university/ (accessed 2015-06-05). 
R. VAn Der Ploeg (2012), Breakthrough Renewables and the Green Paradox, CESifo Working Paper No. 3986, Munich, November.

R. Van Der Ploeg And C. Withagen (2010), Is There Really a Green Paradox?, CESifo Working Paper.

A. Venables (2011), Depletion and Development: Natural Resource Supply with Endogenous Field Opening, OxCarre Research Paper 62, Oxford, June.

J. Whalley And R. Wigle (1991), The International Incidence of Carbon Taxes, in R.Dornbusch And J.M.Poterba (ed.), Global Warming: Economic Policy Responses, pp. 233 - 262, MIT Press.

G.F. WILl (2015), 'Sustainability' Gone Mad on College Campuses, Washington Post, 15 Apr 2015, http://www . washingtonpost.com/opinions/sustainability-gone-mad/ 2015/04/15/f4331bd2-e2da-11e4-905f-cc896d379a32_story.html (accessed 201506-05). 


\section{Annex}

\section{A Planner's choice}

In Lagrangian form, the global planner's problem (17) can be written

$$
\begin{aligned}
\mathcal{L} \equiv & \sum_{r} h_{r} \mathrm{E}_{s}\left[u\left(y_{r}\right)\right]+\lambda_{1}\left[\sum_{r} h_{r} f_{r}-\sum_{r} h_{r} x_{r}\right]+\lambda_{2}\left[\sum_{r} h_{r} f_{r}-\sum_{r} h_{r} z_{r}\right] \\
& +\mathrm{E}_{s}\left[\lambda_{3}(s) \sum_{r}\left[h_{r}\left(v\left(f_{r}\right)-R c\left(x_{r}\right)-k(s) z_{r}-y_{r}(s)\right)-\omega_{r} D(F)\right]\right] .
\end{aligned}
$$

The FOCs yield

$$
\begin{aligned}
\frac{\partial \mathcal{L}}{\partial f_{r}} \stackrel{!}{=} 0: & \lambda_{1}+\lambda_{2}+\mathrm{E}\left[\lambda_{3}(s)\right]\left(v^{\prime}\left(f_{r}\right)-\sum_{r r} \omega_{r r} D^{\prime}(F)\right)=0 \\
\frac{\partial \mathcal{L}}{\partial x_{r}} \stackrel{!}{=} 0: & -\lambda_{1}-\mathrm{E}\left[\lambda_{3}(s)\right] R c^{\prime}\left(x_{r}\right)=0 \\
\frac{\partial \mathcal{L}}{\partial z_{r}} \stackrel{!}{=} 0: & -\lambda_{2}-\mathrm{E}\left[\lambda_{3}(s) k(s)\right]=0 \\
\frac{\partial \mathcal{L}}{\partial y_{r}(s)} \stackrel{!}{=} 0: & \alpha e^{-\alpha y_{r}(s)}-\lambda_{3}(s)=0 \\
\frac{\partial \mathcal{L}}{\partial \lambda_{1}} \stackrel{!}{=} 0: & \sum_{r} h_{r}\left(f_{r}-x_{r}\right)=0 \\
\frac{\partial \mathcal{L}}{\partial \lambda_{2}} \stackrel{!}{=} 0: & \sum_{r} h_{r}\left(f_{r}-z_{r}\right)=0 \\
\frac{\partial \mathcal{L}}{\partial \lambda_{3}(s)} \stackrel{!}{=} 0: & \sum_{r}\left[h_{r}\left(v\left(f_{r}\right)-R c\left(x_{r}\right)-k(s) z_{r}-y_{r}(s)\right)-\omega_{r} D(F)\right]=0 .
\end{aligned}
$$

Eqs. (A.1a), (A.1b) and (A.1e) show that there exists a $f^{w}$ so that $f_{r}=x_{r}=f^{w},(\mathrm{~A} .1 \mathrm{~d})$ implies the existence of a $y^{w}(s)$ so that $y_{r}(s)=y^{w}(s)$, and (A.1f) implies $\sum_{r} h_{r} z_{r}=f^{w}$. Using these and substituting further the shadow values, allows rewriting (A.1a) as

$$
\mathrm{E}\left[e^{-\alpha y^{w}(s)}\right]\left(v^{\prime}\left(f^{w}\right)-R c^{\prime}\left(f^{w}\right)-\sum_{r} \omega_{r} D^{\prime}(F)\right)=\mathrm{E}\left[e^{-\alpha y^{w}(s)} k(s)\right]
$$

and simplifying (A.1g) to

$$
y^{w}(s)=v\left(f^{w}\right)-R c\left(f^{w}\right)-k(s) f^{w}-\sum_{r} \omega_{r} D(F) .
$$

We can simplify (A.2) by dividing both sides by the deterministic part of the exponential after substituting $y^{w}$ using (A.3). Using further the rule that for any $\tilde{Z} \sim N(0,1)$, and 
$\sigma, \sigma_{2} \geq 0$

$$
\mathrm{E}[\underbrace{(\mu+\sigma \tilde{Z})}_{\sim N(\mu, \sigma)} \exp \underbrace{\left(\mu_{2}+\sigma_{2} \tilde{Z}\right)}_{\sim N\left(\mu_{2}, \sigma_{2}\right)}]=\left(\mu+\sigma \cdot \sigma_{2}\right) \exp \left(\mu_{2}+\frac{\sigma_{2}^{2}}{2}\right),
$$

eq. (A.2) ultimately solves to

$$
\begin{aligned}
& \underbrace{v^{\prime}\left(f^{w}\right)}=\underbrace{R c^{\prime}\left(f^{w}\right)}+\underbrace{\sum_{r} \omega_{r} D^{\prime}\left(f^{w}\right)}+\underbrace{\alpha \sigma^{2} f^{w}}, \\
& \text { marginal con- marginal extrac- } \\
& \text { sumption value tion cost }
\end{aligned}
$$

or

$$
f^{w} \alpha \sigma^{2}=v^{\prime}\left(f^{w}\right)-R c^{\prime}\left(f^{w}\right)-\sum_{r} \omega_{r} D^{\prime}\left(f^{w}\right)
$$

\section{B Leakage rates and price reactions}

Consider a passive region with fuel-activity levels according to (13), not imposing any taxes, in an initial equilibrium with fuel and resource prices $p^{0}$ and $q^{0}$. We denote its percapita activity levels implied by (13) for $\tau=0, f^{0}=f\left(p^{0}\right), x^{0}=x\left(q^{0}\right), z^{0}=z\left(p^{0}-R q^{0}\right)$. Relative to this initial state "0", let the region face an external change in the market: a fixed, small reduction in the levels of specific fuel-market activities in the remainder of the world. Denote the absolute foreign reductions $\left(\Delta_{f}, \Delta_{x}, \Delta_{z}\right) \rightarrow 0$ for fuel consumption, deposit offer, and fuel investment, respectively, or in per-capita terms of the (not-small) passive region $\left(\delta_{f}, \delta_{x}, \delta_{z}\right) \equiv \frac{\left(\Delta_{f}, \Delta_{x}, \Delta_{z}\right)}{h} \rightarrow 0$, with $h$ the size of the passive region.

We index with "1" the new equilibrium this change entails, with fuel and resource prices $p^{1}$ and $q^{1}$, and domestic activity levels $f^{1}=f\left(p^{1}\right), x^{1}=x\left(q^{1}\right), z^{1}=z\left(p^{1}-R q^{1}\right)$. Market clearances (11), which apply in both situations, imply that the foreign reductions entail certain changes in the passive region's relative activity levels,

$$
\begin{aligned}
& f^{1}-f^{0}-\delta_{f}=x^{1}-x^{0}-\delta_{x} \\
& f^{1}-f^{0}-\delta_{f}=z^{1}-z^{0}-\delta_{z} .
\end{aligned}
$$

We rewrite this using first-order Taylor approximations for the activity changes,

$$
\begin{aligned}
f\left(p^{1}\right)-f\left(p^{0}\right) & =f^{\prime}\left(p^{0}\right)\left(p^{1}-p^{0}\right) \\
x\left(q^{1}\right)-x\left(q^{0}\right) & =x^{\prime}\left(q^{0}\right)\left(q^{1}-q^{0}\right) \\
z\left(p^{1}-R q^{1}\right)-z\left(p^{0}-R q^{0}\right) & =z^{\prime}\left(p^{0}-R q^{0}\right)\left(p^{1}-p^{0}-\left(q^{1}-q^{0}\right) R\right),
\end{aligned}
$$


yielding

$$
\begin{aligned}
& f^{\prime}\left(p^{0}\right)\left(p^{1}-p^{0}\right)-\delta_{f}=x^{\prime}\left(q^{0}\right)\left(q^{1}-q^{0}\right)-\delta_{x} \\
& f^{\prime}\left(p^{0}\right)\left(p^{1}-p^{0}\right)-\delta_{f}=z^{\prime}\left(p^{0}-R q^{0}\right)\left(p^{1}-p^{0}-\left(q^{1}-q^{0}\right) R\right)-\delta_{z} .
\end{aligned}
$$

This allows to derive the price change $p^{1}-p^{0}$. Eq. (B.6) shows $R z^{\prime} \cdot\left(q^{1}-q^{0}\right)=\left(p^{1}-p^{0}\right)\left(z^{\prime}-\right.$ $\left.f^{\prime}\right)-\delta_{z}+\delta_{f}$. Usage in (B.5) yields $p^{1}-p^{0}=\frac{1}{f^{\prime}}\left[\frac{x^{\prime}}{R z^{\prime}}\left(\left(p^{1}-p^{0}\right)\left(z^{\prime}-f^{\prime}\right)-\delta_{z}+\delta_{f}\right)-\delta_{x}+\delta_{f}\right]$. This solves to

$$
p^{1}-p^{0}=\frac{1}{f^{\prime}} \frac{\left(\frac{R}{x^{\prime}}+\frac{1}{z^{\prime}}\right) \delta_{f}-\frac{R}{x^{\prime}} \delta_{x}-\frac{1}{z^{\prime}} \delta_{z}}{\frac{R}{x^{\prime}}+\frac{1}{z^{\prime}}-\frac{1}{f^{\prime}}} .
$$

For fuel consumption, (B.4a) therefore yields

$$
f^{1}-f^{0}=\frac{\left(\frac{R}{x^{\prime}}+\frac{1}{z^{\prime}}\right) \delta_{f}-\frac{R}{x^{\prime}} \delta_{x}-\frac{1}{z^{\prime}} \delta_{z}}{\frac{R}{x^{\prime}}+\frac{1}{z^{\prime}}-\frac{1}{f^{\prime}}} .
$$

Using (B.7) in (B.5), and replacing $x^{\prime} \cdot\left(q^{1}-q^{0}\right)$ with its asymptotic equivalent $x^{1}-x^{0}$ using (B.4b), yields, with some basic algebra

$$
x^{1}-x^{0}=\frac{\frac{1}{f^{\prime}} \delta_{f}+\left(\frac{1}{z^{\prime}}-\frac{1}{f^{\prime}}\right) \delta_{x}-\frac{1}{z^{\prime}} \delta_{z}}{\frac{R}{x^{\prime}}+\frac{1}{z^{\prime}}-\frac{1}{f^{\prime}}} .
$$

We have $z^{\prime} \cdot\left(p^{1}-p^{0}-\left(q^{1}-q^{0}\right) R\right)$ as the asymptotic equivalent of $z^{1}-z^{0}$. We first substitute $q^{1}-q^{0}=\left(p^{1}-p^{0}\right) \frac{f^{\prime}}{x^{\prime}}+\frac{\delta_{x}-\delta_{f}}{x^{\prime}}$ obtained from (B.5), and then substitute $p^{1}-p^{0}$ using (B.7), yielding

$$
z^{1}-z^{0}=\frac{\frac{1}{f^{\prime}} \delta_{f}-\frac{R}{x^{\prime}} \delta_{x}+\left(\frac{R}{x^{\prime}}-\frac{1}{f^{\prime}}\right) \delta_{z}}{\frac{R}{x^{\prime}}+\frac{1}{z^{\prime}}-\frac{1}{f^{\prime}}} .
$$

The leakage rates implied by the foreign activity reductions, defined in (29) as the ratio of absolute activity increase in the passive region over the absolute reduction in the same activity, can be written as $\mathrm{LR}_{g}=\frac{\partial\left[h g^{1}\right]}{\partial\left[\Delta_{g}\right]}=\frac{\partial g^{1}}{\partial \delta_{g}}$ for $g \in\{f, x, z\}$. The marginal response $\frac{\partial g^{1}}{\partial \delta_{g}}$ of passive-region activity levels to foreign changes in the same activities, are pinned down by (B.8)-(B.10), yielding

$$
\begin{aligned}
& \mathrm{LR}_{f}=\frac{\frac{R}{x^{\prime}}+\frac{1}{z^{\prime}}}{\frac{R}{x^{\prime}}+\frac{1}{z^{\prime}}-\frac{1}{f^{\prime}}}=\frac{-f^{\prime}}{\frac{1}{\frac{R}{x^{\prime}}+\frac{1}{z^{\prime}}-f^{\prime}},}, \\
& \mathrm{LR}_{x}=\frac{\frac{1}{z^{\prime}}-\frac{1}{f^{\prime}}}{\frac{R}{x^{\prime}}+\frac{1}{z^{\prime}}-\frac{1}{f^{\prime}}}=\frac{\frac{x^{\prime}}{R}}{\frac{x^{\prime}}{R}+\frac{1}{\frac{1}{z^{\prime}}-\frac{1}{f^{\prime}}}}, \\
& \mathrm{LR}_{z}=\frac{\frac{R}{x^{\prime}}-\frac{1}{f^{\prime}}}{\frac{z^{\prime}}{x^{\prime}}+\frac{1}{z^{\prime}}-\frac{1}{f^{\prime}}}=\frac{\frac{1}{\frac{R}{x^{\prime}}-\frac{1}{f^{\prime}}}+z^{\prime}}{} .
\end{aligned}
$$


The fuel-price reaction to absolute foreign activity reductions implied by (B.7) are

$$
\begin{aligned}
\frac{\partial p^{1}}{\partial \Delta_{f}} & =\quad \frac{1}{f^{\prime}} \frac{1}{h} \frac{\frac{R}{x^{\prime}}+\frac{1}{z^{\prime}}}{\frac{R}{x^{\prime}}+\frac{1}{z^{\prime}}-\frac{1}{f^{\prime}}}=-\frac{1}{h} \frac{1}{\frac{1}{\frac{R}{x^{\prime}}+\frac{1}{z^{\prime}}}-f^{\prime}}, \\
\frac{\partial p^{1}}{\partial \Delta_{x}} & =-\frac{1}{f^{\prime}} \frac{1}{h} \frac{\frac{R}{x^{\prime}}}{\frac{R}{x^{\prime}}+\frac{1}{z^{\prime}}-\frac{1}{f^{\prime}}}, \\
\frac{\partial p^{1}}{\partial \Delta_{z}} & =-\frac{1}{f^{\prime}} \frac{1}{h} \frac{\frac{1}{z^{\prime}}}{\frac{R}{x^{\prime}}+\frac{1}{z^{\prime}}-\frac{1}{f^{\prime}}} .
\end{aligned}
$$

The resource-price reactions follow from (B.9) and (B.4b),

$$
\frac{\partial q^{1}}{\partial \Delta_{f}}=\frac{1}{x^{\prime}} \frac{1}{h} \frac{\frac{1}{f^{\prime}}}{\frac{R}{x^{\prime}}+\frac{1}{z^{\prime}}-\frac{1}{f^{\prime}}}, \quad \frac{\partial q^{1}}{\partial \Delta_{f}}=\frac{1}{x^{\prime}} \frac{1}{h} \frac{\frac{1}{z^{\prime}}-\frac{1}{f^{\prime}}}{\frac{R}{x^{\prime}}+\frac{1}{z^{\prime}}-\frac{1}{f^{\prime}}}, \quad \frac{\partial q^{1}}{\partial \Delta_{f}}=-\frac{1}{x^{\prime}} \frac{1}{h} \frac{\frac{1}{z^{\prime}}+\frac{1}{z^{\prime}}-\frac{1}{f^{\prime}}}{.}
$$

\section{Correlated alternative risky asset}

Consider the model from the main text but with a possibility of a positive, alternative non-fuel ('other') equity investment $o \geq 0$ in stage 1 . It yields a normally distributed return in stage 2 . To emphasize the analogy with the fuel-investment, we express this return as $R_{o}-k_{o}(s)$, where $R_{o}$ is a constant and $k_{o} \sim N\left(0, \sigma_{o}\right)$. Let $\gamma \equiv \operatorname{corr}\left(k, k_{o}\right)$, equal to the correlation between the returns (or 'extra-costs') from fuel and other equity investments. In this case, the agent's consumption index from (8) becomes

$$
\begin{aligned}
y_{r}^{d}= & \left(R q-\tau_{x}^{r}\right) x_{r}-R c\left(x_{r}\right)+v\left(f_{r}\right)-\left(p+\tau_{f}^{r}\right) f_{r}+\left(p-R q-k(s)-\tau_{z}^{r}\right) z_{r} \\
& +\left(R_{o}-R-k_{o}(s)\right) o_{r}+T_{r}-\frac{\omega_{r}}{h_{r}} D(F) .
\end{aligned}
$$

\section{Decentralized choices}

Let $g$ here be the extended set of all activities, $g \in\{f, x, z, o\}$. We consider decentralized activity choices $g_{r}^{*}$, maximizing the utility derived from private consumption $y_{r}^{d}$, taking prices and climate damage as given, $g_{r}^{*} \equiv \arg \max _{g_{r}} \mathrm{E}_{s}\left[u\left(y_{r}^{d}\right)\right]$. Mean and standard deviation of the normally distributed $y_{r}^{d}$ in (C.12) are here $\mu_{y, r}=\left(R q-\tau_{x}^{r}\right) x_{r}-R c\left(x_{r}\right)+v\left(f_{r}\right)-$ $\left(p+\tau_{f}^{r}\right) f_{r}+\left(p-R q-\tau_{z}^{r}\right) z_{r}+\left(R_{o}-R\right) o+T_{r}-\frac{\omega_{r}}{h_{r}} D(F)$ and $\sigma_{y, r}=\sqrt{\sigma^{2} z_{r}^{2}+\sigma_{o}^{2} o_{r}^{2}+2 \gamma \sigma \sigma_{o} z_{r} o_{r}}$. With $u$ from (10), this allows to re-write the problem as $g_{r}^{*}=\arg \max _{g_{r}} \alpha \mu_{y_{r}}-\frac{1}{2} \alpha^{2} \sigma_{y_{r}}^{2}$. The FOCs yield

$$
\begin{aligned}
f_{r}^{*}\left(p+\tau_{f}^{r}\right) & =\left\{f \mid v^{\prime}(f)=p+\tau_{f}^{r}\right\}, \\
x_{r}^{*}\left(q-\tau_{x}^{r} / R\right) & =\left\{x \mid c^{\prime}(x)=q-\frac{\tau_{x}^{r}}{R}\right\}, \\
z_{r}^{*}\left(p-R q-\tau_{z}^{r}\right) & =\frac{p-R q-\tau_{z}^{r}}{\alpha \sigma^{2}}-\gamma \frac{\sigma_{o}}{\sigma} o_{r}, \\
o_{r} & =\frac{R_{o}-R}{\alpha \sigma_{o}^{2}}-\gamma \frac{\sigma}{\sigma_{o}} z_{r},
\end{aligned}
$$


and (C.13c) and (C.13d) together solve to

$$
\begin{aligned}
z_{r} & =\frac{p-R q-\tau_{z}^{r}}{\left(1-\gamma^{2}\right) \alpha \sigma^{2}}-\frac{\gamma}{1-\gamma^{2}} \frac{R_{o}-R}{\alpha \sigma \sigma_{o}} \\
o_{r} & =\frac{R_{o}-R}{\left(1-\gamma^{2}\right) \alpha \sigma_{o}^{2}}-\frac{\gamma}{1-\gamma^{2}} \frac{p-R q-\tau_{z}^{r}}{\alpha \sigma \sigma_{o}}
\end{aligned}
$$

The price-responsiveness of the decentrally chosen fuel-market activities implied by (C.13a), (C.13b) and (C.13c) are

$$
\begin{aligned}
f_{r}^{* \prime}\left(p+\tau_{f}^{r}\right) & =\frac{1}{v^{\prime \prime}\left(f_{r}^{*}\right)}<0, \\
x_{r}^{* \prime}\left(q-\tau_{x}^{r} / R\right) & =\frac{1}{c^{\prime \prime}\left(x_{r}^{*}\right)}>0, \\
z_{r}^{* \prime}\left(p-R q-\tau_{z}^{r}\right) & =\frac{1}{\left(1-\gamma^{2}\right) \alpha \sigma^{2}}>0 .
\end{aligned}
$$

Using (C.13b) and (C.13a) to substitute $p$ and $q$ in (C.13c), we find

$$
z_{r}^{*}=\frac{v^{\prime}\left(f_{r}^{*}\right)-R c^{\prime}\left(x_{r}^{*}\right)-\tau_{f}^{r}-\tau_{x}^{r}-\tau_{z}^{r}}{\left(1-\gamma^{2}\right) \alpha \sigma^{2}}-\frac{\gamma}{1-\gamma^{2}} \frac{R_{o}-R}{\alpha \sigma \sigma_{o}} .
$$

\section{Global laissez-faire}

Absent taxation, $\tau_{g}^{r}=0$, the decentralized solution from (C.13a), (C.13b) and (C.13c) is symmetric across regions, so that market clearance (11) implies that the six fuel market activity levels take on the same value, $x_{r}, f_{r}, z_{r}=f^{l} \forall r$. Substitution in (C.15) gives

$$
f^{l}=\frac{v^{\prime}\left(f^{l}\right)-R c^{\prime}\left(f^{l}\right)}{\left(1-\gamma^{2}\right) \alpha \sigma^{2}}-\frac{\gamma}{1-\gamma^{2}} \frac{R_{o}-R}{\alpha \sigma \sigma_{o}} .
$$

The LHS is strictly increasing and the RHS strictly decreasing in $f$, so any possible interior solution must be unique. Compared to the case in the main text, the conditions for the existence of this interior solution are here complicated by the correlation with the risky alternative asset. Two conditions must be met. A choke condition, i.e. the requirement that at least some minimal extraction is worthwhile, $\lim _{f \rightarrow 0} v^{\prime}(f)-R c^{\prime}(f)>$ $\gamma \frac{\sigma}{\sigma_{o}}\left(R_{o}-R\right)$, as well as a fuel-consumption finiteness condition, $\exists f<\infty \mid v^{\prime}(f)-R c^{\prime}(f)<$ $\gamma \frac{\sigma}{\sigma_{o}}\left(R_{o}-R\right)$. The fuel-consumption finiteness condition is trivially met for finite resources operationalized by assuming $\exists x<\infty \mid c^{\prime}(x)=\infty$. We illustrate the relationship between the two risky assets contingent on correlation and returns with a discussion of four distinct, theoretically possible cases, pointing out how the risky alternative asset impacts the choke condition in each of them:

- If fuel and non-fuel risks are positively correlated, $\gamma>0$, and the non-fuel asset $o$ yields an excess return compared to the riskless investment, $R_{o}>R$, the existence 
of $o$ tightens the choke condition, as with a positive investment in $o$, a non-marginal risk-premium is required for fuel-investment, already for the first units.

- If fuel and non-fuel risks are negatively correlated, $\gamma<0$, and the non-fuel asset $o$ yields an excess return compared to the risk-free return, $R_{o}>R$, the existence of $o$ relaxes the choke condition: For marginal-only fuel-investment, the excess nonfuel return warrants a strictly positive amount of risky non-fuel investment, and the negative correlation makes the first units of fuel-investment more lucrative, by virtue of partial risk-neutralization.

- If fuel and non-fuel risks are negatively correlated, $\gamma<0$, and the non-fuel asset $o$ yields a return short of the risk-free return, $R_{o}<R$, risky non-fuel investment would implicitly be negative at a low-enough level of fuel investment, but become positive in an equilibrium with high enough fuel-investment, to which the non-fuel asset is complementary in risk-terms. The theoretically negative level of non-fuel investment in the hypothetical situation of marginal-only fuel-investment means the negative correlation tightens the choke condition.

- If fuel and non-fuel risks are positively correlated, $\gamma>0$, and the non-fuel asset $o$ yields a return short of the risk-free return, $R_{o}<R$, the algebra used here implicitly implied a negative investment into non-fuel risky assets independently of the level of fuel-investment, as seen in (C.13d). We do not further consider this case, but if it was allowed, it would relax the choke condition.

\section{Planner's choice}

In Lagrangian form, the global planner's problem of maximizing the population-weighted welfare can be written

$$
\begin{aligned}
\mathcal{L} \equiv & \sum_{r} h_{r} \mathrm{E}_{s}\left[u\left(y_{r}\right)\right]+\lambda_{1}\left[\sum_{r} h_{r} f_{r}-\sum_{r} h_{r} x_{r}\right]+\lambda_{2}\left[\sum_{r} h_{r} f_{r}-\sum_{r} h_{r} z_{r}\right] \\
& +\mathrm{E}_{s}\left[\lambda_{3}(s) \sum_{r}\left[h_{r}\left(v\left(f_{r}\right)-R c\left(x_{r}\right)-k(s) z_{r}+\left(R_{o}-R-k_{o}(s)\right) o_{r}-y_{r}(s)\right)-\omega_{r} D(F)\right]\right]
\end{aligned}
$$


where $F$ is the shortcut for absolute global emissions, $F \equiv \sum_{r} h_{r} f_{r}$. The FOCs yield

$$
\begin{aligned}
\frac{\partial \mathcal{L}}{\partial f_{r}} \stackrel{!}{=} 0: & \lambda_{1}+\lambda_{2}+\mathrm{E}\left[\lambda_{3}(s)\right]\left(v^{\prime}\left(f_{r}\right)-\sum_{r r} \omega_{r r} D^{\prime}(F)\right)=0 \\
\frac{\partial \mathcal{L}}{\partial x_{r}} \stackrel{!}{=} 0: & -\lambda_{1}-\mathrm{E}\left[\lambda_{3}(s)\right] R c^{\prime}\left(x_{r}\right)=0 \\
\frac{\partial \mathcal{L}}{\partial z_{r}} \stackrel{!}{=} 0: & -\lambda_{2}-\mathrm{E}\left[\lambda_{3}(s) k(s)\right]=0 \\
\frac{\partial \mathcal{L}}{\partial o_{r}} \stackrel{!}{=} 0: & \mathrm{E}\left[\lambda_{3}(s)\left(R_{o}-R-k_{o}(s)\right)\right]=0 \\
\frac{\partial \mathcal{L}}{\partial y_{r}(s)} \stackrel{!}{=} 0: & \alpha e^{-\alpha y_{r}(s)-\lambda_{3}(s)=0} \\
\frac{\partial \mathcal{L}}{\partial \lambda_{1}} \stackrel{!}{=} 0: & \sum_{r} h_{r}\left(f_{r}-x_{r}\right)=0 \\
\frac{\partial \mathcal{L}}{\partial \lambda_{2}} \stackrel{!}{=} 0: & \sum_{r} h_{r}\left(f_{r}-z_{r}\right)=0 \\
\frac{\partial \mathcal{L}}{\partial \lambda_{3}(s)} \stackrel{!}{=} 0: & \sum_{r}\left[h _ { r } \left(v\left(f_{r}\right)-R c\left(x_{r}\right)-k(s) z_{r}\right.\right. \\
& \left.\left.+\left(R_{o}-R-k_{o}(s)\right) o_{r}-y_{r}(s)\right)-\omega_{r} D(F)\right]=0 .
\end{aligned}
$$

Eqs. (C.17a), (C.17b) and (C.17f) show that there exists a $f^{w}$ so that $f_{r}=x_{r}=f^{w}$, (C.17e) implies the existence of a $y^{w}(s)$ so that $y_{r}(s)=y^{w}(s)$, and (C.17g) implies $\sum_{r} h_{r} z_{r}=f^{w}$. Using these and substituting further the shadow values, allows rewriting (C.17a) as

$$
\mathrm{E}\left[e^{-\alpha y^{w}(s)}\right]\left(v^{\prime}\left(f^{w}\right)-R c^{\prime}\left(f^{w}\right)-\sum_{r} \omega_{r} D^{\prime}(F)\right)=\mathrm{E}\left[e^{-\alpha y^{w}(s)} k(s)\right]
$$

and simplifying (C.17h) to

$$
y^{w}(s)=v\left(f^{w}\right)-R c\left(f^{w}\right)-k(s) f^{w}+\sum_{r} h_{r} o_{r} \cdot\left(R_{o}-R-k_{o}(s)\right)-\sum_{r} \omega_{r} D(F) .
$$

Using (C.17e) and replacing $y_{r}$ by the equivalent $y^{w}$ from (C.19), (C.17d) yields

$$
\mathrm{E}\left[\alpha e^{-\alpha\left[v\left(f^{w}\right)-R c\left(f^{w}\right)-k(s) f^{w}+\sum_{r} h_{r} o_{r} \cdot\left(R_{o}-R-k_{o}(s)\right)-\sum_{r} \omega_{r} D(F)\right]}\left(R_{o}-R-k_{o}(s)\right)\right]=0 .
$$

Using further a particular bivariate-normal rule for correlated normal variables, $\tilde{Z}, \tilde{Z}^{\prime} \sim$ $N(0,1), \operatorname{corr}\left(Z, Z^{\prime}\right)=\gamma$, and $\sigma, \sigma_{2} \sigma_{3} \geq 0$,

$$
\mathrm{E}[\underbrace{(\mu+\sigma \tilde{Z})}_{\sim N(\mu, \sigma)} \exp (\underbrace{\mu_{2}+\sigma_{2} \tilde{Z}}_{\sim N\left(\mu_{2}, \sigma_{2}\right)} \underbrace{+\sigma_{3} \tilde{Z}^{\prime}}_{\sim\left(0, \sigma_{3}\right)})]=\left(\mu+\sigma\left(\sigma_{2}+\gamma \sigma_{3}\right)\right) \exp \left(\mu_{2}+\frac{\sigma_{2}^{2}}{2}+\frac{\sigma_{3}^{2}}{2}+\gamma \sigma_{2} \sigma_{3}\right),
$$


eq. (C.20) yields

$$
\sum_{r} h_{r} o_{r}=\frac{R_{o}-R}{\alpha \sigma_{o}^{2}}-\gamma \frac{\sigma}{\sigma_{o}} f^{w} .
$$

We can simplify (C.18) by dividing both sides by the deterministic part of the exponential after substituting $y^{w}$ using (C.19). Using also here the particular bivariate-normal rule for correlated normal variables just applied before, (C.18) ultimately solves to

$$
\begin{aligned}
& \underbrace{v^{\prime}\left(f^{w}\right)}=\underbrace{R c^{\prime}\left(f^{w}\right)}+\underbrace{\sum_{r} \omega_{r} D^{\prime}\left(f^{w}\right)}+\underbrace{\alpha \sigma\left(\sigma f^{w}+\gamma \sigma_{o} \sum_{r} h_{r} o_{r}\right)}, \\
& \text { marginal con- marginal extrac- } \quad \text { marginal emission risk adjustment for marginal } \\
& \text { sumption value tion cost } \quad \text { cost investment }
\end{aligned}
$$

or

$$
f^{w}=\frac{v^{\prime}\left(f^{w}\right)-R c^{\prime}\left(f^{w}\right)-\sum_{r} \omega_{r} D^{\prime}\left(f^{w}\right)}{\alpha \sigma^{2}}-\gamma \frac{\sigma_{o}}{\sigma} \sum_{r} h_{r} o_{r} .
$$

Analogously to the case without the alternative equity investment, a comparison to the decentralized choices, (C.13a), (C.13b), and (C.13c) shows that any set of taxes such that $\tau_{f}^{w}+\tau_{x}^{w}+\tau_{z}^{w}=D^{\prime}\left(f^{w}\right) \sum_{r} \omega_{r}$ yields the globally optimal fuel market activity levels.

\section{Unilateral policy}

Consider the setup of section 4.1, with $a$ the active small open economy and $b$ the passive remainder of the world. Using (C.15) instead of (14) from the case without alternative equity, (C.21) here changes to

$$
f_{b}, x_{b}, z_{b} \approx \frac{v^{\prime}\left(f_{b}\right)-R c^{\prime}\left(x_{b}\right)}{\left(1-\gamma^{2}\right) \alpha \sigma^{2}}-\frac{\gamma}{1-\gamma^{2}} \frac{R_{o}-R}{\alpha \sigma \sigma_{o}}
$$

Similarly to the case in the main text, we see that region $b$ choices approach those of the present global laissez-faire from (C.16),

$$
f_{b}, x_{b}, z_{b} \approx f^{l}
$$

and the market prices become

$$
\begin{aligned}
& p=v^{\prime}\left(f_{b}\right) \approx v^{\prime}\left(f^{l}\right) \\
& q=c^{\prime}\left(x_{b}\right) \approx c^{\prime}\left(x^{l}\right) .
\end{aligned}
$$

The outcome described by (C.21)-(C.22b) varies only marginally with choices in the small region $a$. Accordingly, region $a$ takes prices $p$ and $q$ as given in the optimization. Its problem of optimal regional behavior, maximizing the utility-value of the regional consumption 
index writes

$\max _{x_{a}, f_{a}, z_{a}} \mathrm{E}_{s}\left[u\left(v\left(f_{a}\right)-f_{a} p-R c\left(x_{a}\right)+R x_{a} q+z_{a}(p-R q-k(s))+\left(R_{o}-R-k_{o}(s)\right) o_{a}-\frac{\omega_{a}}{h_{a}} D(F)\right)\right]$ subject to $F=\sum_{r} h_{r} f_{r}=\sum_{r} h_{r} x_{r}=\sum_{r} h_{r} z_{r}$.

Calculations analogous to those for the decentralized choices in section $\mathrm{C}$ show that the FOCs for the three fuel activities yield

$$
\begin{aligned}
v^{\prime}\left(f_{a}\right) & \stackrel{!}{\approx} p+\omega_{a} D^{\prime}(F)\left(1+\frac{h_{b}}{h_{a}} \frac{\partial f_{b}}{\partial f_{a}}\right), \\
R c^{\prime}\left(x_{a}\right) & \stackrel{!}{\approx} R q-\omega_{a} D^{\prime}(F)\left(1+\frac{h_{b}}{h_{a}} \frac{\partial x_{b}}{\partial x_{a}}\right), \\
z_{a} & \stackrel{!}{\approx} \frac{p-R q-\omega_{a} D^{\prime}(F)\left(1+\frac{h_{b}}{h_{a}} \frac{\partial z_{b}}{\partial z_{a}}\right)}{\left(1-\gamma^{2}\right) \alpha \sigma^{2}}-\frac{\gamma}{1-\gamma^{2}} \frac{R_{o}-R}{\alpha \sigma \sigma_{o}}
\end{aligned}
$$

and for the alternative equity investment level the FOC gives

$$
o_{r} \stackrel{!}{\approx} \frac{R_{o}-R}{\left(1-\gamma^{2}\right) \alpha \sigma_{o}^{2}}-\frac{\gamma}{1-\gamma^{2}} \frac{p-R q-\omega_{a} D^{\prime}(F)\left(1+\frac{h_{b}}{h_{a}} \frac{\partial z_{b}}{\partial z_{a}}\right)}{\alpha \sigma \sigma_{o}}
$$

We see that decentralized behavior for region $a,($ C.13a)-(C.13b) and (C.13c)-(C.13d), leads to these optimal regional choices for taxes of the form in (28), with LR the leakage rates from (29). The calculation in Annex B applies, yielding (30) for the leakage rates attached to exogenous reductions of region $a$ 's fuel use, resource offer, and fuel investment, respectively, and implying the taxes (32). Together with the price-responsiveness of the market activity levels, (C.14), the leakage rates here develop to

$$
\begin{aligned}
\mathrm{LR}_{f} & \approx \frac{-v^{\prime \prime}\left(f^{l}\right)^{-1}}{\left[c^{\prime \prime}\left(f^{l}\right) R+\left(1-\gamma^{2}\right) \alpha \sigma^{2}\right]^{-1}-v^{\prime \prime}\left(f^{l}\right)^{-1}}, \\
\mathrm{LR}_{x} & \approx \frac{\left[c^{\prime \prime}\left(f^{l}\right) R\right]^{-1}}{c^{\prime \prime}\left(f^{l}\right) R+\left[\left(1-\gamma^{2}\right) \alpha \sigma^{2}-v^{\prime \prime}\left(f^{l}\right)\right]^{-1}}, \\
\mathrm{LR}_{z} & \approx \frac{\left[\left(1-\gamma^{2}\right) \alpha \sigma^{2}\right]^{-1}}{\left[c^{\prime \prime}\left(f^{l}\right) R-v^{\prime \prime}\left(f^{l}\right)\right]^{-1}+\left[\left(1-\gamma^{2}\right) \alpha \sigma^{2}\right]^{-1}},
\end{aligned}
$$

and the regionally optimal taxes become

$$
\begin{aligned}
\tau_{f}^{u} & \approx \omega_{a} D^{\prime}\left(f^{l}\right) \frac{-v^{\prime \prime}\left(f^{l}\right)}{R c^{\prime \prime}\left(f^{l}\right)+\left(1-\gamma^{2}\right) \alpha \sigma^{2}-v^{\prime \prime}\left(f^{l}\right)}, \\
\tau_{x}^{u} & \approx \omega_{a} D^{\prime}\left(f^{l}\right) \frac{R c^{\prime \prime}\left(f^{l}\right)}{R c^{\prime \prime}\left(f^{l}\right)+\left(1-\gamma^{2}\right) \alpha \sigma^{2}-v^{\prime \prime}\left(f^{l}\right)} \\
\tau_{z}^{u} & \approx \omega_{a} D^{\prime}\left(f^{l}\right) \frac{\left(1-\gamma^{2}\right) \alpha \sigma^{2}}{R c^{\prime \prime}\left(f^{l}\right)+\left(1-\gamma^{2}\right) \alpha \sigma^{2}-v^{\prime \prime}\left(f^{l}\right)},
\end{aligned}
$$


with the same qualitative implications as in section 4.1, notably $\sum_{g=\{f, x, z\}} \tau_{g}=\omega_{a} D^{\prime}\left(f^{l}\right)$. The effect of the correlated alternative asset is to augment the investment risk coefficient $\alpha \sigma^{2}$ by the factor $1-\gamma^{2}$ in the optimal tax and leakage rate expressions. The intuition behind this result is as follows: with a correlation of zero, $\gamma=0$, the alternative risky asset has no effect on the fuel market in our framework; taxes and leakage remain the same as without the alternative risky asset. If correlation is perfect and negative, $\gamma=-1$ (positive, $\gamma=+1$ ), a fuel risk increase can be perfectly diversified against by means of alternative investment increases (decreases), so that risk concern does not inhibit foreign investors to fully offset domestic fuel investment changes. In this case the entire effect of the fuel-risk vanishes from the leakage and optimal tax expressions; the optimal tax on investment becomes zero. Cases with non-zero, non-perfect correlation lie in between these extremes.

\section{Imperfectly correlated risk}

We consider a continuum of small deposits. Their size can be operationalized as a size $\varepsilon=\frac{1}{n}$ for $n \rightarrow \infty$, when we split any given amount $m$ of resource deposit into $m n$ individual deposits, so that their total size becomes $m n \varepsilon=m$. Each small deposit has a normal handling cost that we express as $N\left(0, \varepsilon^{2} \sigma_{\varepsilon}^{2}\right)$, with finite and non-marginal $\sigma_{\varepsilon}^{2}$. We denote the correlation between any two deposit's returns as $\gamma$, with $0<\gamma<1$ for the imperfect correlation of returns across deposits. An individual investor minimizes risk by spreading his (regional or global) investment across a large number of (regional or global) deposits; for example across all of them. This minimizes the variance of the handling cost he has to pay, and thus of his net return, making this wide spread across deposits the dominant strategy.

Consider an amount $x_{r}$ of global investments in regions $r=\{a, b\}$, and the investors of a region investing for a (per-capita) amount $m$ of resources, with a regional split $m=m_{a}+m_{b}$. In this case, it is easy to verify that - as a sum over a large number of small, imperfectly correlated normals - the distribution of the aggregate handling cost $K_{m r}$ for the representative investor becomes

$$
K_{m r} \sim N\left(0, \gamma m^{2} \sigma_{\varepsilon}^{2}\right)
$$

independently of the exact interregional split $m_{r}$ of the investment or of the exact size of $x_{r}$. It follows from (D.26) that the distribution of the handling cost $K_{m r}$ from investment into an amount $m$ of resource deposit has the same distribution as in the case of a homogenous 
handling cost considered in the main text, when the per-unit cost distribution is

$$
k \sim N\left(0, \gamma \sigma_{\varepsilon}^{2}\right)
$$

so that $m k$ is distributed as (D.26). One can further verify that smallness of individual deposits guarantees that the economic agents fully extract in each region the first $x_{r} n$ deposits with the lowest standard extraction costs $c_{r}^{\prime}(x)$, rather than spreading the extraction over a larger set of deposits to be extracted partly. ${ }^{15}$ The analysis of the main text thus remains valid, when the variance $\sigma^{2}$ from (9) is $\gamma \sigma_{\varepsilon}^{2}$, i.e. proportional to the correlation factor $\gamma$.

\footnotetext{
${ }^{15}$ Such a spreading to fields beyond the set of 'cheapest' deposits would be warranted if the imperfectly correlated individual fields were large instead: in this case, diversification against lumpy risk warranted opening some fields partly on the margin if the differences in the deterministic cost component are sufficiently small.
} 